\title{
Religion and Intergroup Boundaries: Positive and Negative Ties Among Youth in Ethnically and Religiously Diverse School Classes in Western Europe
}

\author{
Müge Simsek $^{1}$ (D) Frank van Tubergen ${ }^{2} \cdot$ Fenella Fleischmann $^{3}$
}

Received: 18 November 2020 / Accepted: 16 September 2021 / Published online: 5 November 2021 (c) The Author(s) 2021

\begin{abstract}
Background In the past decades, Western European countries have become increasingly religiously diverse; furthermore, a growing share of their population is now youth with a migration background. Little is known about the role religion plays in social ties among children of native and immigrant origins.

Purpose This study examines religious group boundaries among youth in secondary schools in England, Germany, the Netherlands, and Sweden. To this end, it describes to what extent youth's positive and negative ties in the classroom are segregated along religious lines. Furthermore, it analyzes the role of structural opportunities and religious in-group preferences in the formation of religious boundaries in the social networks of youth.

Methods The data come from the first wave of the Children of Immigrants Longitudinal Survey in Four European Countries (CILS4EU), which contains more than 18,000 adolescents (aged 14-15) in England, Germany, the Netherlands, and Sweden. First, we describe overall religious segregation in the social ties of youth by using the full survey data. Second, we test our hypotheses by analyzing the complete social networks of 5236 students in 247 classes.

Results The analysis reveals that friendships are more likely between classmates with similar religious affiliations than classmates with different religious affiliations. In particular, in terms of friendships, there is clear segregation between non-religious and Christian youth on the one hand and Muslim youth on the other. This segregation is partly driven by structural forces that constrain intergroup meeting opportunities. However, group segregation goes beyond the patterns expected from opportunities alone. The results show strong preferences for intrareligious friendships and a tendency to avoid ties between Muslim and non-Muslim youth.

Conclusion and Implications There are religious boundaries in the social relationships of youth in ethnically and religiously diverse school classes in Western Europe. In particular, social boundaries between Muslim and non-Muslim youth are the strongest. Creating opportunities for positive intergroup contact, such as the promotion of religiously diverse schools, apparently is not sufficient to avoid religious
\end{abstract}

Extended author information available on the last page of the article 
boundaries among youth. To reduce segregation along religious lines, interventions would also need to address the factors that shape youth's preferences for intrareligious friendships.

Keywords Immigrant religion - Religious boundaries - Immigrant integration · Social networks · Muslims in Europe

\section{Introduction}

In the past decades, Western European countries have become more religiously diverse as a result of immigration from highly religious and often non-Christian societies (van Tubergen and Sindradottir 2011). In particular, the rise of the Muslim population is striking (Voas and Fleischmann 2012), as many immigrants were born in largely Islamic countries like Turkey, Morocco, and Pakistan. The growing presence of the immigrant population has become a key issue in European public debates. A pressing question is whether immigrants will successfully integrate into mainstream society, with much of the concern directed toward Muslim immigrants and the (in)compatibility of Islamic faith and traditions with the liberal, secular culture of the West (Foner 2015; Foner and Alba 2008; Zolberg and Woon 1999).

To understand the role of religion in the integration processes of immigrants, scholars have studied symbolic and social boundaries between European host nationals and immigrants. Symbolic boundaries refer to the cognitive categorizations used by majority groups to define "us" and "them" whereas social boundaries are revealed in patterns of social interaction between different groups, such as ethnic segregation and social exclusion (Lamont and Molnar 2002; Wimmer 2008). A large body of evidence highlights religion as both a symbolic and a social divide separating Muslim immigrants from other immigrant groups and mainstream society (Drouhout and Nee 2019). For example, it has been found that Western European majority populations are more hostile toward Muslims than immigrants in general (Doebler 2014; Simonsen and Bonikowski 2020; Strabac and Listhaug 2008), that there are rather few marriages between Muslim immigrants and non-Muslims (Lucassen and Laarman 2009), and that Muslims are discriminated in the labor market (Adida et al. 2016; Bartkoski et al. 2018; Blommaert et al. 2014; Di Stasio et al. 2019).

A limitation of prior work is that most studies have been concerned with the foreign-born adult population. However, the offspring of these immigrants-the second generation-has become a major demographic group in Western societies (Eurostat 2011). Research indicates that religious transmission in immigrant families, especially Islamic ones, is strong (de Hoon and van Tubergen 2014; Jacob and Kalter 2013), which means that many children of highly religious (Muslim) immigrants consider themselves as religious, too. To date, little is known about the consequences of their religion on the integration process.

We contribute to previous literature by studying religious boundaries in the social relations of youth. We pay special attention to social boundaries among Muslim, 
Christian and non-religious youth. The context of our study is schools and the ties that adolescents have in this setting. We build on a growing literature that has used social network data from complete school classes to study ethnic boundaries in friendship ties (Baerveldt et al. 2007; Kruse et al. 2016; Mayer and Puller 2008; Moody 2001; Munniksma et al. 2017; Smith et al. 2014, 2016; Wimmer and Lewis 2010; Zeng and Xie 2008) and negative ties (Tolsma et al. 2013; Wittek et al. 2019).

We go beyond the few studies that examined religious boundaries in social ties at school (Leszczensky and Pink 2017; Smith et al. 2016; Windzio and Wingens 2014). First, we use large-scale national surveys rather than data from specific regions in a single country, such as Bremen (Windzio and Wingens 2014) or North Rhine-Westphalia (Leszczensky and Pink 2017), to get a more representative picture of religious boundaries among youth in Western Europe. We use the Children of Immigrants Longitudinal Survey in Four European Countries (CILS4EU), which contains data on 18,716 students, aged 14-15 years old, who attend secondary schools in England, Germany, the Netherlands, and Sweden (Kalter et al. 2016). As our data include samples of children of native and immigrant origin, ${ }^{1}$ we can examine ties between Muslim, Christian, and non-religious groups with diverse ethnic backgrounds.

Second, we study not only positive ties — best friends in class - as in earlier work (Leszczensky and Pink 2017; Smith et al. 2016; Windzio and Wingens 2014) but also negative ones - those next to whom youth do not want to sit. Studying these ties simultaneously allows for a more comprehensive understanding of religious boundaries among youth, as the processes of connecting and distancing jointly contribute to the emergence of social boundaries (Wimmer 2008). Importantly, the concerns about the lack of integration between Muslims and non-Muslims may be more serious if it appears that there are not only few interreligious friendship ties but also, or even more so, if members of both groups actively avoid each other. In addition, it is important to know the relationship between positive and negative intergroup interactions in religiously diverse settings. For example, if youth from different religious groups tend to dislike one another, increased opportunities for intergroup contacts in school may at the same time increase the chances for negative intergroup interactions, thereby possibly offsetting the positive consequences. In short, studying positive and negative ties concurrently rather than in isolation can offer better insights for policies aiming to facilitate positive intergroup interactions.

The aim of this study is twofold. First, descriptively, it attempts to document the degree to which friendship ties and negative ties in schools are segregated along religious lines in England, Germany, the Netherlands, and Sweden. Second, theoretically, it aims to unravel the processes that link religion to the segregation of social ties. For the descriptive part, we use the full data from the survey, which are

\footnotetext{
1 We infer migration background from self-reported ethnicity. Accordingly, a person is regarded as a "child of native origin" if he/she self-identifies with the ethnicity of the majority group, e.g., English, German, Dutch, or Swedish, and a "child of immigrant origin" otherwise. The main advantage of using self-reported ethnicity over other alternative measures (e.g., country of birth (of ancestors) or nationality), is that it allows for a more nuanced categorization of ethnicity and consequently a more refined measure of (ethnic) homophily.
} 
nationally representative for youth aged 14-15. In our inferential analyses, we focus on a subsample of 5236 students in 247 school classes in the four countries.

\section{National Religious Contexts}

England, Germany, the Netherlands, and Sweden are all historically Christian countries. Today, however, they are among the most secularized in the world (e.g., Burkimsher 2014; Norris and Inglehart 2011). According to our calculations based on the data from the European Social Survey (2014), religiously unaffiliated people comprise around $70 \%$ of the population in Sweden, $60 \%$ in the Netherlands, $50 \%$ in England, and $40 \%$ in Germany. In addition, levels of religious involvement among the general population are rather low in the four countries. For example, in England, Germany, and the Netherlands, only 8-13\% attend religious services once a week or more and $17-20 \%$ pray every day. In Sweden, the corresponding percentages are even lower, at $5 \%$ and $8 \%$, respectively. In light of these numbers, it can be said that Sweden is the most secular of the four countries. Altogether, all four countries have a significant proportion of people that are not affiliated with any religion and that do not practice religion regularly.

At the same time, the four countries are characterized by increasing levels of religious diversity as a result of high rates of immigration. In the past couple of decades, these countries have seen an influx of immigrants from Christian majority countries, such as Russia, Poland, and Italy, and Muslim majority ones, such as Turkey, Morocco, Pakistan, and Iraq (de Haas et al. 2019). Overall, immigrant populations have higher levels of religiosity than the majority populations in the four countries we study (van Tubergen and Sindradottir 2011).

\section{Religion and Tie Formation}

We study how religion relates to social boundaries among youth by examining the patterns of religious segregation in peer relationships in class. In doing so, we differentiate gross from net group segregation. Gross group segregation refers to the observed social boundaries between members of different (religious) groups when not taking into consideration opportunities for intergroup contact. After accounting for these opportunities, one obtains net group segregation, which is more indicative of individual choices in connecting and distancing. Overall, disentangling gross and net segregation enables us to understand the mechanisms that give rise to religious group boundaries among youth.

The structural opportunity argument asserts that social ties are made in context, such as schools and neighborhoods, and that the composition of the social context plays a role in promoting or hindering intergroup ties (Blau 1977; Blau et al. 1982; Kalmijn 1998). This means, for example, that opportunities to become friends or foes with people from another group increase with the relative size of that out-group in school. In this study, we examine how youth create ties within the school context while taking into account the structural opportunities that drive tie formation. 
After accounting for meeting opportunities, we expect to see net group segregation related to religion because of homophily and heterophobia. A longstanding line of research has argued that people have a preference to befriend similar others (Byrne 1961; Kandel 1978; McPherson et al. 2001). More specifically, similarity in sociodemographic characteristics, such as education, ethnicity, gender, religion, and age, as well as shared beliefs, values, and personality traits, facilitate interpersonal communication and thus govern preferences in relationship formation (McPherson et al. 2001).

Religion represents a particular collection of values and beliefs about sacred things from which people derive rituals and a certain way of living. Importantly, beliefs and practices associated with a religion are inherently common to those who adhere to it (Durkheim 1912/2008, p. 46). If members of the same religion are similar according to a variety of beliefs and behaviors, then, following the principles of homophily, they will be more likely to befriend each other than those outside their religion. Therefore, our first hypothesis is:

Hypothesis 1 Classmates who are dissimilar in terms of religious affiliation are less likely to have positive ties with each other than classmates who are similar in terms of religious affiliation.

We argue that the homophily principle applies also to the formation of negative ties but in a reversed manner, such that those who are dissimilar are more likely to avoid and dislike each other. In light of the numerous religious conflicts across the globe, it is not difficult to see how religion can be a source of intergroup intolerance and aggression. Research has shown that negative attitudes toward religious others are prevalent across different religious groups (Jackson and Hunsberger 1999; Johnson et al. 2012). We therefore derive the following hypothesis:

Hypothesis 2 Classmates who are dissimilar in terms of religious affiliation are more likely to have negative ties with each other than classmates who are similar in terms of religious affiliation.

However, neither homophily nor heterophobia might be equally strong toward all out-groups. Specifically, considering the strong anti-Muslim attitudes in Europe (Doebler 2014; Simonsen and Bonikowski 2020; Strabac and Listhaug 2008), Muslim youth might be particularly disliked by others and boundaries between Muslim and non-Muslim youth might be stronger than between other groups. Accordingly, we hypothesize that the boundary between Muslim and non-Muslim youth is stronger than between other groups.

Hypothesis 3 Muslim and non-Muslim (i.e., Christian or non-religious) classmates are less likely to have positive ties (a) and more likely to have negative ties (b) with each other than other classmates. 
Table 1 Number of schools, classes and students (by religious group) in CILS4EU, wave 1

\begin{tabular}{lrrrr}
\hline & EN & GE & NL & SW \\
\hline Schools & 107 & 144 & 100 & 129 \\
Classes & 208 & 271 & 222 & 251 \\
Students & 4315 & 5013 & 4363 & 5025 \\
Non-religious & 1634 & 598 & 2301 & 1444 \\
Christian & 1470 & 2879 & 1030 & 2211 \\
Muslim & 525 & 1182 & 648 & 779 \\
Other & 395 & 224 & 327 & 163 \\
Missing & 291 & 130 & 57 & 428 \\
\hline
\end{tabular}

$\mathrm{EN}=$ England, $\mathrm{GE}=$ Germany, $\mathrm{NL}=$ the Netherlands, $\mathrm{SW}=$ Sweden

\section{Data}

The data come from the first wave of CILS4EU (Kalter et al. 2016). CILS4EU is a stratified longitudinal study of structural, social, and cultural integration among 14to 15-year-old youth with and without a migration background. The survey began in 2010/2011 with in-school questionnaires administered to 18,716 students in 958 classes of 480 schools in England, Germany, the Netherlands, and Sweden. Schools were stratified according to their proportion of children of immigrants in the relevant age group in order to guarantee the desired number of children of immigrants in the sample. Subsequently, two classes within each school were selected via simple random sampling; the overall response rate for students was $86.9 \%$. More information on the data collection process and the response rates can be found in the technical reports (CILS4EU 2016a, b). Table 1 shows the number of schools, classes, and students as well as the distribution of students across religious groups.

The CILS4EU data include sociometric classroom information that captures students' complete classroom networks. We listwise delete 6.6\% $(N=1238)$ of cases due to missing values ${ }^{2}$ and exclude two classes $(N=28)$ due to problems during the data collection process. ${ }^{3}$ To obtain a descriptive picture of gross group segregation, it is important to have a sample that is nationally representative. Therefore, when presenting the descriptive results below, we rely on this full sample. The share of each religious group (per class) for this full sample can be found in Table 6 in "Appendix 1".

When we subsequently turn to the tests of the hypotheses, we focus on a more selective sample. We select only those classes that have more than $10 \mathrm{stu}-$ dents and that are not completely homogenous in relation to the covariates of

\footnotetext{
${ }^{2}$ Religious affiliation was missing in $4.8 \%$ of cases and religious importance, frequency of praying, and attending religious services had missing values in $5.2 \%, 5.0 \%$, and $5.0 \%$ of cases, respectively. Gender was missing in $0.07 \%$ of cases while only $0.01 \%$ of cases had missing values on ethnicity.

3 In these two classrooms only, students were allowed to nominate friends outside the class.
} 
interest $\left(N_{\text {class }}=247, N_{\text {student }}=5236\right)$. Given that we are interested in specific religious boundaries (e.g., do Christian youth befriend Muslim youth?), we select classes with at least one student from each religious affiliation (non-religious, Christian, Muslim, and other). Because we control for ethnic and gender homophily, classes should have at least one boy, one girl, one student of native origin, and one student of immigrant origin.

Our outcome variables are positive and negative ties among classmates. Positive ties were measured by asking 'Who are your best friends in class?'. Students were not allowed to write down more than five names. Additionally, students were asked about their negative ties with the question 'Who would you not want to sit next to?' and could nominate at most five classmates. ${ }^{4}$ Regarding both positive and negative ties, we included both reciprocal and non-reciprocal nominations in our analysis. This means that a positive or negative tie is considered as realized if ego nominates alter as a friend or as someone whom he/she does not want to sit next to (directed tie). Lastly, students who were absent in the class on the day of the questionnaire could be nominated, but we could not take these nominations into account in the analysis as all other relevant information on these students was missing. ${ }^{5}$

In the questionnaire, religious affiliation was asked as 'What is your religion?' and had seven categories as answers: no religion, Buddhism, Christianity, Hinduism, Islam, Judaism, Sikhism, and other. Due to sparsely populated cells, we recoded affiliations into four categories, namely, non-religious, Christian, Muslim, and other. ${ }^{6}$ Because youth may differ in their intensity of religious commitment, we also include a measure of religiosity as a control variable. The questionnaire contains three items tapping into different aspects of religiosity, namely, subjective importance of religion, frequency of visiting religious meeting places, and frequency of praying. Principal-component factor analysis for these three items yielded a single factor $(\alpha=0.84)$. Accordingly, we rescaled all three items first to a range between 0 and 1 and then averaged the scores on the rescaled items to obtain a composite measure of religiosity. Table 7 in "Appendix 1" provides a detailed explanation of other individual and dyad level variables used in the analyses.

\footnotetext{
${ }^{4}$ In preliminary analyses we had used two additional items for negative ties, namely, "Who is sometimes mean to you?" and "Who are you sometimes mean to?". The results from these analyses were similar to those from the analyses with the single item, i.e., not wanting to sit together. However, because some students nominated some of their best friends as persons who are mean to them and/or who they are mean to, we were unsure whether these nominations could be considered negative relationships and therefore opted to use only the nominations for the more clearly negative item "Who would you not want to sit next to?" in our final analyses.

${ }^{5}$ Approximately $6 \%$ of all nominations were deleted based on absence.

${ }^{6}$ Because the 'other' religious affiliations consist of a heterogenous group of religions, we refrain from interpreting the findings for this group.
} 
Table 2 Intra- and interreligious social ties in class

\begin{tabular}{|c|c|c|c|c|c|c|c|}
\hline \multirow{2}{*}{$\begin{array}{l}\text { Religion } \\
\text { respondent }\end{array}$} & \multirow{2}{*}{$\begin{array}{l}\text { Population } \\
(\%)\end{array}$} & \multicolumn{3}{|c|}{$\%$ of their positive ties are with... } & \multicolumn{3}{|c|}{$\%$ of their negative ties are with... } \\
\hline & & Non-religious & Christian & Muslim & Non-religious & Christian & Muslim \\
\hline \multicolumn{8}{|l|}{ England } \\
\hline Non-religious & 49.67 & 58.64 & 35.24 & 1.95 & $\mathbf{5 7 . 5 6}$ & 32.63 & 4.08 \\
\hline Christian & 38.43 & 41.50 & 50.31 & 2.71 & 46.33 & 43.52 & 4.01 \\
\hline Muslim & 5.88 & 20.72 & 19.65 & 49.75 & 32.37 & 25.01 & 33.72 \\
\hline \multicolumn{8}{|l|}{ Germany } \\
\hline Non-religious & 16.89 & 43.76 & 49.35 & 4.13 & 43.47 & 46.50 & 6.45 \\
\hline Christian & 70.35 & 12.04 & 80.23 & 4.53 & 10.71 & 78.97 & 6.80 \\
\hline Muslim & 8.94 & 8.48 & 41.08 & 43.85 & 14.23 & 58.62 & 22.41 \\
\hline \multicolumn{8}{|l|}{ Netherlands } \\
\hline Non-religious & 53.88 & 64.18 & 27.55 & 2.80 & 62.13 & 26.86 & 4.82 \\
\hline Christian & 34.97 & 42.15 & 51.13 & 1.82 & 39.59 & 44.89 & 2.53 \\
\hline Muslim & 4.72 & 36.40 & 15.97 & 36.35 & 49.22 & 19.83 & 22.96 \\
\hline \multicolumn{8}{|l|}{ Sweden } \\
\hline Non-religious & 36.93 & 48.99 & 45.25 & 3.31 & 42.42 & 46.29 & 6.91 \\
\hline Christian & 52.47 & 32.91 & 60.37 & 4.35 & 35.83 & 51.79 & 8.25 \\
\hline Muslim & 7.69 & 17.85 & 35.08 & 43.91 & 25.51 & 42.37 & 29.32 \\
\hline
\end{tabular}

Data are weighted for sampling design. $\mathrm{EN}=$ England, $\mathrm{GE}=$ Germany, $\mathrm{NL}=$ the Netherlands, $\mathrm{SW}=\mathrm{Swe}-$ den. Diagonal values are highlighted in bold. The small group of 'other religion' is omitted from the tables, which explains that percentages may not add up to $100 \%$

Bold is just to higlight the diagonal cells in the table

\section{Results}

\section{Gross Religious Group Boundaries}

We first present a descriptive picture of gross religious group boundaries in classroom networks, that is, the gross group segregation in positive and negative ties among youth of different religions. Gross group boundaries reflect the pattern we observe when not taking opportunities for intergroup contact into consideration, which make up students' daily reality. Table 2 displays the percentages of in-class intra- and interreligious social ties per religious group. We compute these percentages based on nationally representative (weighted) data.

We find, first, that Christian and non-religious youth are mainly friends with other Christian and non-religious classmates or with each other; they have very few Muslim friends. To illustrate, in Germany, $80 \%$ of the friends of Christian youth are Christian, $12 \%$ are non-religious, and only 5\% are Muslim. In England, 59\% of the friends of non-religious youth are non-religious, 35\% are Christian, and only 2\% are Muslim.

A second finding is that the friendship network of Muslims is much more diverse than that of Christian and non-religious youth. Muslim youth tend to befriend Muslims but they also have many friends that are non-religious and Christian. For example, in Sweden, 44\% of Muslim youth have friends who are Muslim, 35\% who are Christian, and $18 \%$ who are non-religious. 
Third, we find that these two patterns are mirrored when examining negative ties, although the religious group boundaries appear slightly less strong. Thus, Christian and non-religious youth not only have most friends within their group or with each other, but they also tend to have negative ties most frequently in their group or with each other, rather than with Muslims. To illustrate, in the Netherlands, $62 \%$ of the negative in-class ties of non-religious youth are with non-religious peers; only $5 \%$ are with Muslims, which is just above the share of positive ties with them (3\%). Likewise, we find that the negative ties of Muslims are more diverse than those of Christian and non-religious youth. However, Muslim youth have far fewer negative ties with Muslims than they have friendships with them. For example, in Germany, only $22 \%$ of the negative ties of Muslim youth are with other Muslims, while $44 \%$ of their friends are Muslim. Such a strong discrepancy between positive and negative ties is not observed among other groups. In Germany, for example, $44 \%$ of the friends of non-religious youth are non-religious and the same percentage of their negative ties is with non-religious peers.

\section{The Role of Population Size}

A key follow-up question is to what extent these gross religious group boundaries in positive and negative ties are shaped by mere opportunity. We look at two opportunity forces: population size (national) and school class composition (local). Table 2 presents the share of each religious group in the population. As can be seen, non-religious and Christian youth make up the largest population in each country, significantly more than the Muslim population. Consequently, their larger numbers may account for the more numerous intrareligious ties, as well as the frequent ties between youth from these two groups. This element may also account for the few ties Christian and non-religious groups have with Muslims.

However, group size in the population cannot fully account for gross religious group boundaries. A consistent finding is that the number of observed intrareligious ties exceeds the number of expected intrareligious ties based on population numbers. For example, whereas $70 \%$ of German youth are Christian, $80 \%$ of their friends are Christian. This discrepancy is largest among Muslims. In the Netherlands, only 5\% of youth are Muslim, but among Muslims, 36\% of their friends are Muslim. In summary, gross religious group boundaries are stronger than expected according to population size.

\section{The Role of School Class Composition}

Opportunities for contact are also dependent on the composition of classes. Children from different religions are sorted in school classes, which provide the immediate context for creating social ties and may thereby also account for gross religious boundaries. Table 3 presents results from regression models in which the share of respondents' intrareligious ties is regressed on the share of intrareligious classmates. We find that this immediate context plays an important role: a one percent increase in co-religious classmates is associated with almost a one percent increase in co-religious positive and negative ties of ego. The percentage of intrareligious classmates accounts for $29-53 \%$ of the variance in the share of intrareligious positive and negative ties. 
Table 3 Regression models predicting the percentage of intrareligious ties of ego in class

\begin{tabular}{|c|c|c|c|c|c|}
\hline & & \multicolumn{2}{|c|}{$\begin{array}{l}\% \text { intrareligious posi- } \\
\text { tive ties of ego }\end{array}$} & \multicolumn{2}{|c|}{$\begin{array}{l}\% \text { intrareligious nega- } \\
\text { tive ties of ego }\end{array}$} \\
\hline & & Coef. (se) & R-squared & Coef. (se) & R-squared \\
\hline \multirow{4}{*}{$\begin{array}{l}\% \text { intrare- } \\
\text { ligious } \\
\text { classmates }\end{array}$} & $\mathrm{EN}$ & $\begin{array}{l}0.930 * * * \\
(0.025)\end{array}$ & 0.363 & $\begin{array}{l}0.939 * * * \\
(0.039)\end{array}$ & 0.300 \\
\hline & GE & $\begin{array}{l}0.983 * * * \\
(0.014)\end{array}$ & 0.488 & $\begin{array}{l}0.952 * * * \\
(0.021)\end{array}$ & 0.452 \\
\hline & NL & $\begin{array}{l}0.968 * * * \\
(0.013)\end{array}$ & 0.529 & $\begin{array}{l}0.951 * * * \\
(0.029)\end{array}$ & 0.438 \\
\hline & SW & $\begin{array}{l}0.936 * * * \\
(0.020)\end{array}$ & 0.376 & $\begin{array}{l}0.892 * * * \\
(0.033)\end{array}$ & 0.289 \\
\hline
\end{tabular}

Data are not weighted for sampling design. Clustered standard errors are presented. $\mathrm{EN}=$ England, $\mathrm{GE}=$ Germany, $\mathrm{NL}=$ the Netherlands, $\mathrm{SW}=$ Sweden

${ }^{\dagger} p<0.1 ; * p<0.05$; ** $p<0.01$; *** $p<0.001$ (two-sided)

In summary, these findings highlight that differences in group size and class composition are important drivers of gross religious boundaries. At the same time, the observed patterns cannot be fully explained by mere opportunity and significant unexplained variance remains.

\section{Net Religious Boundaries}

When the sizes of different religious groups in the class are taken into account, we obtain the net religious boundaries of students' networks, which reveal more about their in- and out-group preferences. One way to capture net group boundaries is using odds ratios, which are insensitive to the distribution of the size of the different religious groups in the class (Moody 2001). To this end, for each religious group, we compute (a) the number of realized ties between members of the same affiliation, (b) the number of ties that are not realized between members of the same affiliation, (c) the number of realized ties between members of different affiliations, and (d) the number of ties that are not realized between members of different affiliations in each school class. The fraction of $\mathrm{a} / \mathrm{b}$ to $\mathrm{c} / \mathrm{d}$ corresponds to the odds of a positive (negative) tie between members of a same-religious dyad relative to the odds of a positive (negative) tie in an interreligious dyad. We combine these ratios across school classes in each country by way of a random-effects meta-analysis.

Figure 1 displays the mean odds ratios across classes with the $95 \%$ confidence intervals around those means. Results indicate that the odds of an intrareligious positive tie are higher than those of an interreligious positive tie for non-religious, Christian, and Muslim youth in all four countries. However, the tendency to create intrareligious friends is much stronger among Muslim youth than among nonreligious and Christian youth. This (partly) explains why Muslim youth have many Muslim friends, despite their fewer numbers. When looking at negative ties, we see that the intrareligious tendencies are less strong for each religious group. 

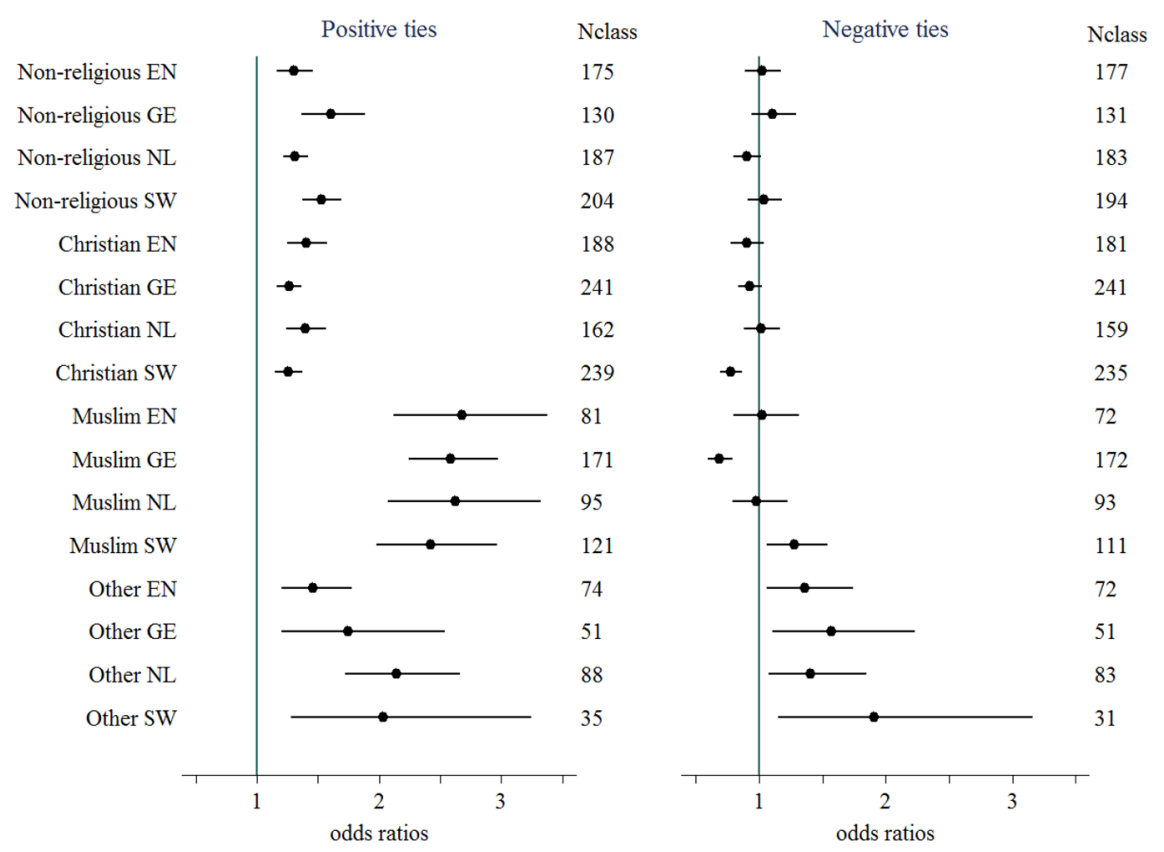

Fig. 1 Odds ratios of a positive (negative) tie between members of a same-religious dyad relative to a positive (negative) tie in a cross-religious dyad. Data are not weighted for sampling design. The 95\% confidence intervals from the random-effects meta-analyses are shown by spikes. EN=England, $\mathrm{GE}=$ Germany, $\mathrm{NL}=$ the Netherlands, $\mathrm{SW}=$ Sweden

\section{Testing Hypotheses on Religious Homophily}

While Fig. 1 provides a good picture of religious group boundaries in youth networks independent of religious group sizes in the class, it does not take into account other ego, dyadic, and class characteristics. In the next step, we consider other characteristics in studying patterns that drive net religious group boundaries. We test the hypotheses using Additive and Multiplicative Random Effects (AME) models ${ }^{7}$ (see "Appendix 2" for sensitivity analysis employing exponential random graph models as an alternative method).

In network analyses, one has to account for interdependencies between observations (e.g., structural dependencies of ties in networks) when estimating the effects of covariates. AME models achieve this through a set of additive and multiplicative effects. Specifically, the additive part of the AME model accounts for variation in the number of nominations made and received by ego and alter as well as the reciprocity of the nominations. The multiplicative part of the model captures the most

\footnotetext{
${ }^{7}$ The Amen package in $\mathrm{R}$ provides the estimation of these models and is available from the CRAN repository at http://cran.r-project.org/web/packages/amen/. Hoff (2015) provides a detailed description of these models. Empirical applications of the models are available in a series of papers (Dorff and Ward 2013; Fosdick and Hoff 2015; Minhas et al. 2016a).
} 
established third-order dependence patterns (e.g., transitive triads and stochastic equivalence) (Minhas et al. 2016a; b). ${ }^{8}$ Third-order dependencies are of particular relevance given that previous research has shown they substantially contribute to tie formation mechanisms; disregarding these dependencies, therefore, may result in the overestimation of homophily coefficients (Wimmer and Lewis 2010). ${ }^{9}$

We follow a two-stage procedure in estimating the homophily coefficients, which is a common method in the analysis of multiple small networks. In the first stage, each class network is analyzed separately; in the second one, the parameter estimates obtained in the first stage are summarized across classes using meta-analysis (Lubbers 2013; Smith et al. 2016; Snijders and Baerveldt 2003).

The dependent variables are 'positive ties' and 'negative ties'; both are measured at the dyadic level. We construct two models for predicting each dependent variable. In models $1 \mathrm{a}$ and $1 \mathrm{~b}$, we include four dyadic covariates. The first variable is 'same religious affiliation', which takes on the value 1 if ego and alter have the same religious affiliation and 0 otherwise. The second variable is "difference in religiosity", which is constructed by calculating the absolute difference between scores of ego and alter on the religiosity scale. Lastly, we include two more homophily measures, namely, 'different ethnicity' and 'different gender' ${ }^{10}$ as control variables (see Table 7 in "Appendix 1" for a detailed description of variables used in the analysis). Aside from dyadic covariates, the models contain eight nodal covariates: ego's and alter's percentage of co-religious classmates; ego's and alter's percentage of co-ethnic classmates; ego's and alter's percentage of same-gender classmates (to account for relevant meeting opportunities in class); ego's and alter's religiosity (as a proxy for meeting opportunities in terms of religiosity and to avoid misspecification of the models).

To study the salience of specific religious boundaries, in Models $2 \mathrm{a}$ and $2 \mathrm{~b}$ (Tables 4, 5) we replace the dummy 'same religious affiliation' with six dummies that capture all possible combinations in which ego's religious affiliation is not the same as alter's affiliation, comparing them to dyads with the same religious affiliation. Otherwise, the models are identical to models $1 \mathrm{a}$ and $1 \mathrm{~b}$. In all the models, the same control variables are used.

In the second stage, we run a univariate random effects meta-analysis to pool the effects over the classes. ${ }^{11}$ In a random effects meta-analysis, the weights assigned to separate class findings depend on both within-study variance and estimated betweenstudy variance. These weights ensure that classes with large standard errors contribute less to the average effect size than classes with small standard errors. In addition, these weights take into account that additional variation across study findings might

\footnotetext{
${ }^{8}$ The mathematical specification of the additive and multiplicative part of these models can be found in "Appendix 3".

9 We also ran our models without allowing for third-order dependencies. A comparison of goodness-offit statistics revealed that taking into account third-order dependencies improves the fit in many classes. This implies that our data bear out the necessity of including these dependencies.

10 We control for gender homophily because same-sex friendships are quite common during adolescence (McPherson et al. 2001; Poulin and Pedersen 2007).

11 Alternative approaches using multivariate random effects meta-analysis yield similar results (see "Appendix 2").
} 


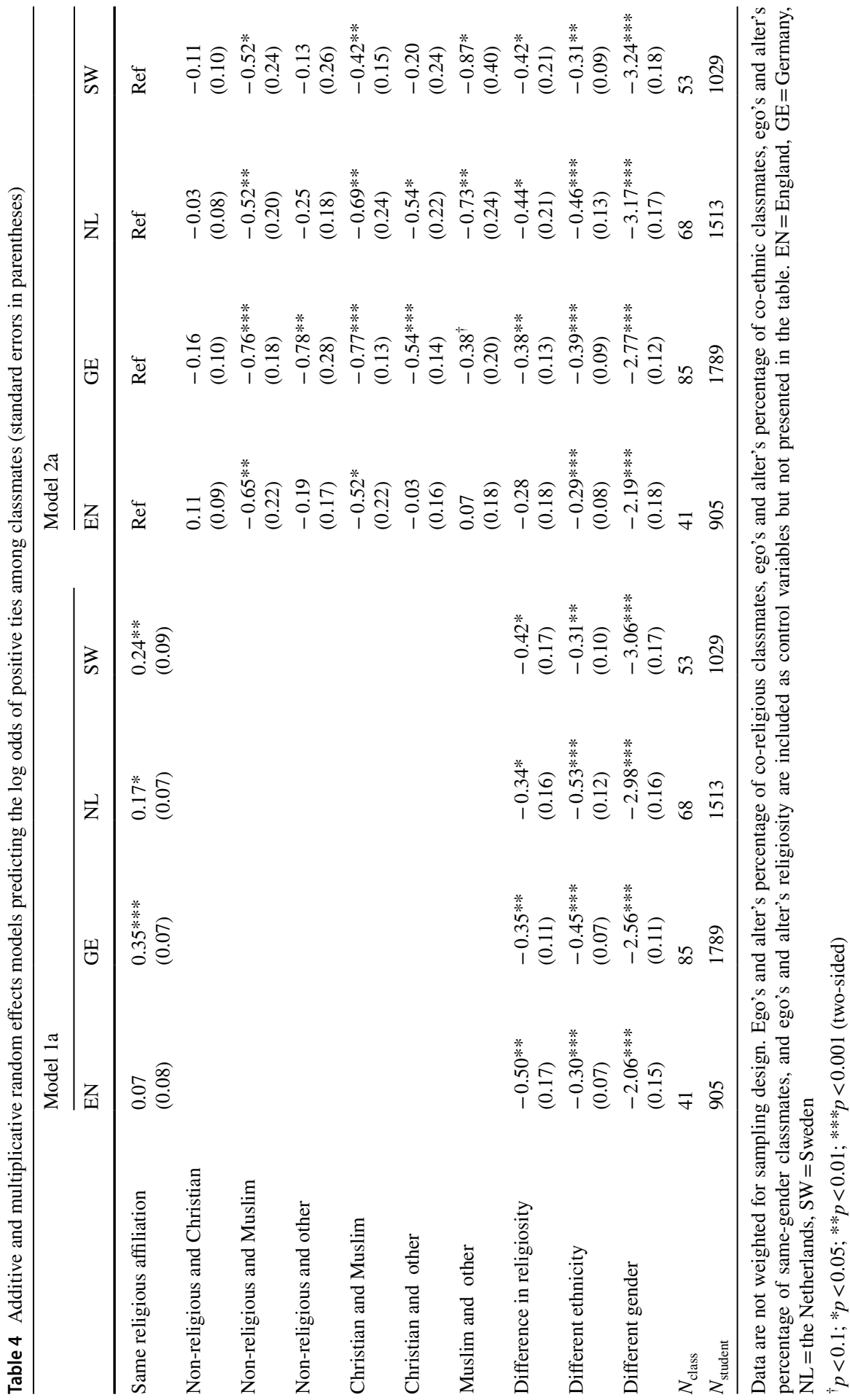


Table 5 Additive and multiplicative random effects models predicting the log odds of negative ties among classmates (standard errors in parentheses)

\begin{tabular}{|c|c|c|c|c|c|c|c|c|}
\hline & \multicolumn{4}{|c|}{ Model 1b } & \multicolumn{4}{|l|}{ Model 2b } \\
\hline & EN & GE & NL & SW & EN & GE & NL & SW \\
\hline $\begin{array}{l}\text { Same religious } \\
\text { affiliation }\end{array}$ & $\begin{array}{l}-0.10 \\
(0.07)\end{array}$ & $\begin{array}{l}-0.05 \\
(0.05)\end{array}$ & $\begin{array}{l}0.02 \\
(0.06)\end{array}$ & $\begin{array}{l}-0.06 \\
(0.08)\end{array}$ & Ref & Ref & Ref & Ref \\
\hline $\begin{array}{l}\text { Non-religious and } \\
\text { Christian }\end{array}$ & & & & & $\begin{array}{l}0.06 \\
(0.12)\end{array}$ & $\begin{array}{l}0.03 \\
(0.09)\end{array}$ & $\begin{array}{l}-0.09 \\
(0.07)\end{array}$ & $\begin{array}{l}0.04 \\
(0.12)\end{array}$ \\
\hline $\begin{array}{l}\text { Non-religious and } \\
\text { Muslim }\end{array}$ & & & & & $\begin{array}{l}0.33 \\
(0.24)\end{array}$ & $\begin{array}{l}0.09 \\
(0.12)\end{array}$ & $\begin{array}{l}0.15 \\
(0.12)\end{array}$ & $\begin{array}{l}0.05 \\
(0.19)\end{array}$ \\
\hline $\begin{array}{l}\text { Non-religious and } \\
\text { other }\end{array}$ & & & & & $\begin{array}{l}0.22 \\
(0.17)\end{array}$ & $\begin{array}{l}0.53^{* *} \\
(0.19)\end{array}$ & $\begin{array}{l}0.04 \\
(0.15)\end{array}$ & $\begin{array}{l}-0.58^{\dagger} \\
(0.34)\end{array}$ \\
\hline $\begin{array}{l}\text { Christian and } \\
\text { Muslim }\end{array}$ & & & & & $\begin{array}{l}0.35^{*} \\
(0.17)\end{array}$ & $\begin{array}{l}0.10 \\
(0.08)\end{array}$ & $\begin{array}{l}0.29^{\dagger} \\
(0.17)\end{array}$ & $\begin{array}{l}0.15 \\
(0.13)\end{array}$ \\
\hline Christian and other & & & & & $\begin{array}{l}0.37^{\dagger} \\
(0.20)\end{array}$ & $\begin{array}{l}0.12 \\
(0.12)\end{array}$ & $\begin{array}{l}-0.24 \\
(0.25)\end{array}$ & $\begin{array}{l}-0.13 \\
(0.27)\end{array}$ \\
\hline Muslim and other & & & & & $\begin{array}{l}0.35^{\dagger} \\
(0.19)\end{array}$ & $\begin{array}{l}-0.08 \\
(0.16)\end{array}$ & $\begin{array}{l}0.27^{\dagger} \\
(0.15)\end{array}$ & $\begin{array}{l}0.21 \\
(0.34)\end{array}$ \\
\hline $\begin{array}{l}\text { Difference in } \\
\text { religiosity }\end{array}$ & $\begin{array}{l}0.20 \\
(0.16)\end{array}$ & $\begin{array}{l}0.19^{*} \\
(0.08)\end{array}$ & $\begin{array}{l}0.02 \\
(0.13)\end{array}$ & $\begin{array}{l}0.28^{\dagger} \\
(0.17)\end{array}$ & $\begin{array}{l}0.01 \\
(0.16)\end{array}$ & $\begin{array}{l}0.19^{*} \\
(0.09)\end{array}$ & $\begin{array}{l}0.14 \\
(0.15)\end{array}$ & $\begin{array}{l}0.31 \\
(0.21)\end{array}$ \\
\hline Different ethnicity & $\begin{array}{l}-0.04 \\
(0.08)\end{array}$ & $\begin{array}{l}0.14^{*} \\
(0.06)\end{array}$ & $\begin{array}{l}-0.01 \\
(0.09)\end{array}$ & $\begin{array}{l}-0.10 \\
(0.08)\end{array}$ & $\begin{array}{l}-0.07 \\
(0.09)\end{array}$ & $\begin{array}{l}0.09 \\
(0.06)\end{array}$ & $\begin{array}{l}-0.10 \\
(0.10)\end{array}$ & $\begin{array}{l}-0.06 \\
(0.09)\end{array}$ \\
\hline Different gender & $\begin{array}{l}0.26 \text { **** } \\
(0.06)\end{array}$ & $\begin{array}{l}0.42 * * * \\
(0.06)\end{array}$ & $\begin{array}{l}0.35^{* * *} \\
(0.09)\end{array}$ & $\begin{array}{l}0.51 * * * \\
(0.12)\end{array}$ & $\begin{array}{l}0.28 * * * \\
(0.07)\end{array}$ & $\begin{array}{l}0.44 * * * \\
(0.07)\end{array}$ & $\begin{array}{l}0.33^{* *} \\
(0.10)\end{array}$ & $\begin{array}{l}0.55^{* * * *} \\
(0.13)\end{array}$ \\
\hline$N_{\text {class }}$ & 41 & 85 & 68 & 53 & 41 & 85 & 68 & 53 \\
\hline$N_{\text {student }}$ & 905 & 1789 & 1513 & 1029 & 905 & 1789 & 1513 & 1029 \\
\hline
\end{tabular}

Data are not weighted for sampling design. Ego's and alter's percentage of co-religious classmates, ego's and alter's percentage of co-ethnic classmates, ego's and alter's percentage of same-gender classmates, and ego's and alter's religiosity are included as control variables but not presented in the table. $\mathrm{EN}=$ England, $\mathrm{GE}=$ Germany, $\mathrm{NL}=$ the Netherlands, $\mathrm{SW}=$ Sweden ${ }^{\dagger} p<0.1 ; * p<0.05 ; * * p<0.01$; *** $p<0.001$ (two-sided)

occur due to differences in the way studies are carried out (Veroniki et al. 2015). We present the effects of primary interest (i.e., the dyadic homophily measures) in the log-odds units in Tables 4 and 5. The full models, including the effects of nodal covariates, can be found in "Appendix 1" (see Tables 9, 10).

The results in Table 4, Model 1a, reveal that in Germany, the Netherlands, and Sweden same-religious positive ties are more likely than cross-religious positive ties, even after taking into account ethnic and gender homophily as well as other control variables. These findings lend support to Hypothesis 1, suggesting that classmates with different religious affiliations are less likely to have positive ties with each other than classmates who have the same religious affiliation.

Model 2a in Table 4 shows that compared to the case in which ego and alter have the same religious affiliation, the odds of a positive tie are 34\%-54\% smaller for a Muslim/Christian dyad and 40\%-53\% smaller for a Muslim/non-religious dyad in all the countries. Importantly, in none of the countries, the likelihood of a positive tie 
differs between when ego and alter are of the same affiliation and when ego(alter) is non-religious and alter(ego) is Christian. Additional analysis (Table 8 in "Appendix 1") further reveals that the odds of a friendship tie between a Muslim and a non-Muslim youth are 34\%-37\% smaller $(p<0.001)$ in Germany and Sweden and $26 \%$ smaller $(p<0.05)$ in the Netherlands compared to other ego-alter combinations. In England, the corresponding odds for a friendship tie in a Muslim/non-Muslim dyad are rather similar to the ones in the Netherlands but fall short of statistical significance $(p=0.067)$. Overall, these findings provide support for Hypothesis 3a, suggesting that Muslims stand out as a group and the boundaries between them and other religious affiliations are the strongest in terms of friendships.

Turning to negative ties, Model $1 \mathrm{~b}$ in Table 5 shows that the discrepancy in religious affiliation does not relate to classmates' reluctance to sit together. This is in contrast to Hypothesis 2, which predicted heterophobia among youth based on religious affiliation. Examining all possible combinations of dyads based on religious affiliation (Model 2b in Table 5), we see that the likelihood of a negative tie between a Christian and a Muslim in England is higher compared to that between a pair of religiously co-affiliated youth. Furthermore, separate analyses (Table 8 in "Appendix 1") show that boundaries between Muslims and non-Muslims are evident in two countries; the odds of a negative tie increase by approximately $28 \%$ in the Netherlands $(p<0.05)$ and $24 \%$ in Sweden when ego (alter) is Muslim and alter(ego) is non-Muslim, compared to other possible ego-alter combinations. These findings give only partial support to Hypothesis $3 \mathrm{~b}$, suggesting that the boundaries between Muslims and non-Muslims are the strongest in terms of negative ties.

\section{Discussion and Limitations}

In this study, we asked whether and how religion relates to social boundaries among youth in four Western European countries. To this end, we examined the complete social networks of youth in secondary school classes. Specifically, we investigated the degree to which youth's positive and negative ties in the classroom are segregated along religious lines. Furthermore, we analyzed the role of structural opportunities (locally and nationally) and religious in-group preferences in the emergence of gross and net religious boundaries in the social networks of youth.

We find that there is strong gross religious segregation between non-religious and Christian youth on one hand and Muslim youth on the other. The pattern of segregation is not symmetric, however. Non-religious and Christian youth have few social ties with Muslims, whereas Muslim youth have many ties with non-religious and Christian peers. Negative ties tend to be subject to the same imbalance, albeit less strongly. In particular, Muslims have more intrareligious friends as compared to intrareligious "foes".

To some extent, this gross segregation between religious groups is driven by structural opportunities to establish intra- and inter-group ties, both at the national level (group size) and the school level. At the level of school classes, we found that group size explains up to $60 \%$ of the variance in religious divides in both positive and negative ties. The small number of Muslims is 'forced' to establish ties outside 
their group, whereas few non-religious and Christian youth have the opportunity to meet and befriend Muslims.

However, structural opportunities, although important, cannot entirely explain gross segregation between religious groups. The findings show that homophily based on religious affiliation is a prevalent phenomenon in the school classes we studied in England, Germany, the Netherlands, and Sweden. This means that even after we control for opportunities for intra- and interreligious contact in the class, and for different dimensions of homophily, youth prefer to befriend intrareligious peers more often than interreligious peers. These results support Hypothesis 1 and highlight that religious homophily is an additional source of group segregation among youth. Moreover, our results support Hypothesis 3a in that Muslim and non-Muslim youth (i.e., Christian or non-religious youth) prefer to befriend each other the least. This reluctance is equally strong between Muslim and non-religious youth and between Muslim and Christian youth. This finding is in contrast to earlier research that found stronger boundaries for the Muslim and non-religious divide than for the Muslim and Christian one (Carol et al. 2015; Trittler 2019).

Regarding negative ties, we do not find a significant or consistent effect of similarity in religious affiliation on the likelihood of negative ties. However, we do find that Muslim and non-Muslim youth prefer not to sit next to each other in the Dutch and Swedish classes we studied. A similar tendency for avoidance is also found between Muslim and Christian youth in England. These findings do not support Hypothesis 2 but lend some support to Hypothesis $3 \mathrm{~b}$ suggesting that boundaries among Muslims and non-Muslims are the strongest. At the same time, these results hint at differences in religious group boundaries across the four countries. Using nationally representative data, future research should consider whether and how national contexts influence the formation of social boundaries along religious lines among youth.

Taken together, these results point out that homophily and heterophobia may not be two sides of the same coin (cf. Boda and Neray 2005; Wittek et al. 2019). It has been suggested that homophilic preferences lead to heterophobia only under specific circumstances in which maintaining one's own positive (in-group) identity depends on discriminating dissimilar others (Dijkstra et al. 2007; Mummendey and Schreiber 1983). Contextual effects (e.g., a competitive classroom atmosphere) that reinforce ingroup preferences and result in avoidance or dislike of out-groups may be lacking in some of the school classes we studied. Future work needs to identify these contextual effects to better understand the emergence of negative ties in relation to the absence of friendships. On a related note, our measures of positive and negative ties rely on different questions and hence are likely to capture ties of different strength (strong positive ties vs weak negative ties). This in turn limits our ability to draw firm conclusions about the nature of the observed relationship between positive and negative ties. Future studies that aim to uncover the relationship between homophily and heterophobia may consider employing more comparable measures for positive and negative ties.

Previous research in Germany, using smaller-scale convenience samples, had shown that Muslims' friendships with Christian and non-religious youth are less common (Lesczcensky and Pink 2017; Windzio and Wingens 2014). Providing similar evidence in Germany, as well as in three other countries with different ethno-religious compositions (Sweden, the Netherlands, and England), our findings 
underline the pervasiveness of social divides between Muslim and non-Muslim youth in Western Europe. These findings, together with the results regarding negative ties, suggest that social boundaries between Muslim and non-Muslim youth are more rigid than previously shown. This highlights the need to focus on studying positive and negative relationships concurrently instead of separately.

Our study has several limitations that warrant further consideration. First, we focused on opportunities only within the class. Classmates, however, may meet each other in settings other than classes (e.g., the neighborhood and social clubs). Therefore, controlling for meeting opportunities outside the class context would help future research map religious boundaries at the classroom level more accurately. Second, previous research has shown that in addition to the two tie formation mechanisms we have examined, third-party influence, particularly from parents, also matters (McPherson et al. 2001; Smith et al. 2014). Due to the low response rate among parents in the parental questionnaire of CILS4EU, we opted to omit parental data from our study. Third, we ran the inferential network models only on a limited number of classes in each country. To some extent, this undermines the representativeness of the CILS4EU sample and the applicability of our results to all school classes in the countries in question. Lastly, we studied one particular type of positive tie (best friends) and one particular type of negative tie (not wanting to sit together). The strength of religious boundaries may depend on the nature and strength of the ties studied. Hence, an interesting question for future research is to examine whether our findings extend to other types of positive and negative ties (e.g., friends of friends, hate, violence).

\section{Conclusion and Implications}

The present study provides evidence that religion matters for positive and negative relationships among youth in ethnically and religiously diverse school classes in Western Europe. In particular, there are strong social boundaries between Christian and non-religious youth on the one hand and Muslim youth on the other. These boundaries are partly a result of limited opportunities for contact between Muslim and non-Muslim youth and partly a result of these youth's choices to befriend or avoid each other. From a policy perspective, creating opportunities for intergroup contacts, e.g., increasing religious diversity in schools, is an important step to overcome religious boundaries among youth. However, this alone is not sufficient, and should be supplemented with interventions that take into account the factors that influence youth's preferences for intrareligious friendships.

\section{Appendix 1: Additional Tables and Figures}

See Tables 6, 7, 8, 9, 10. 


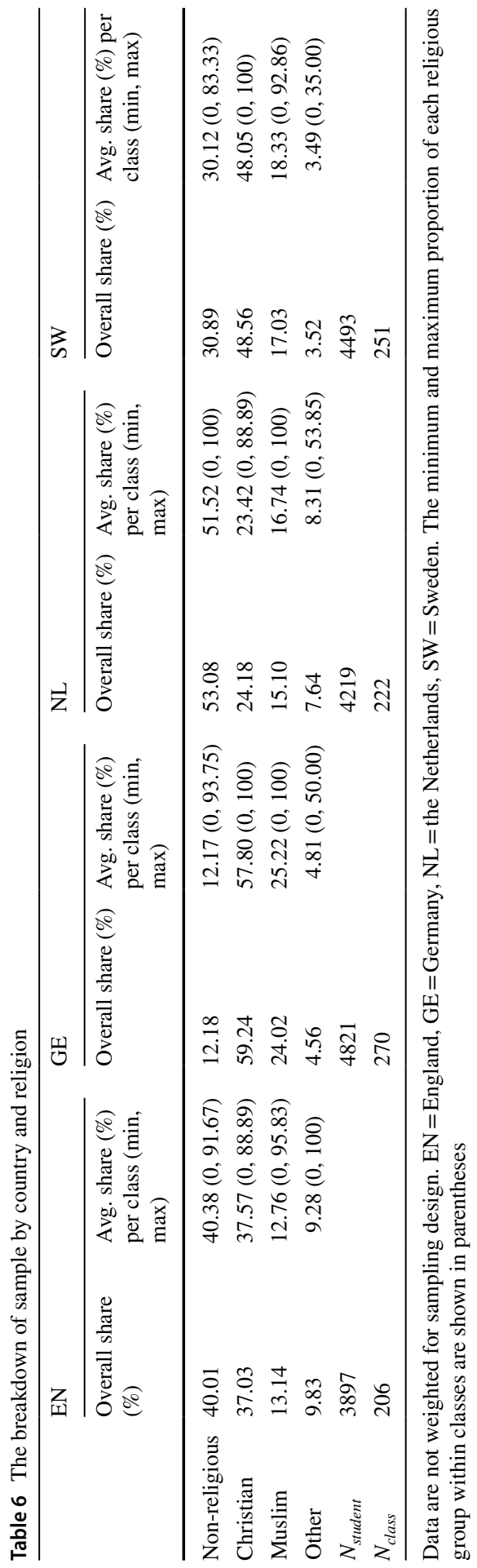




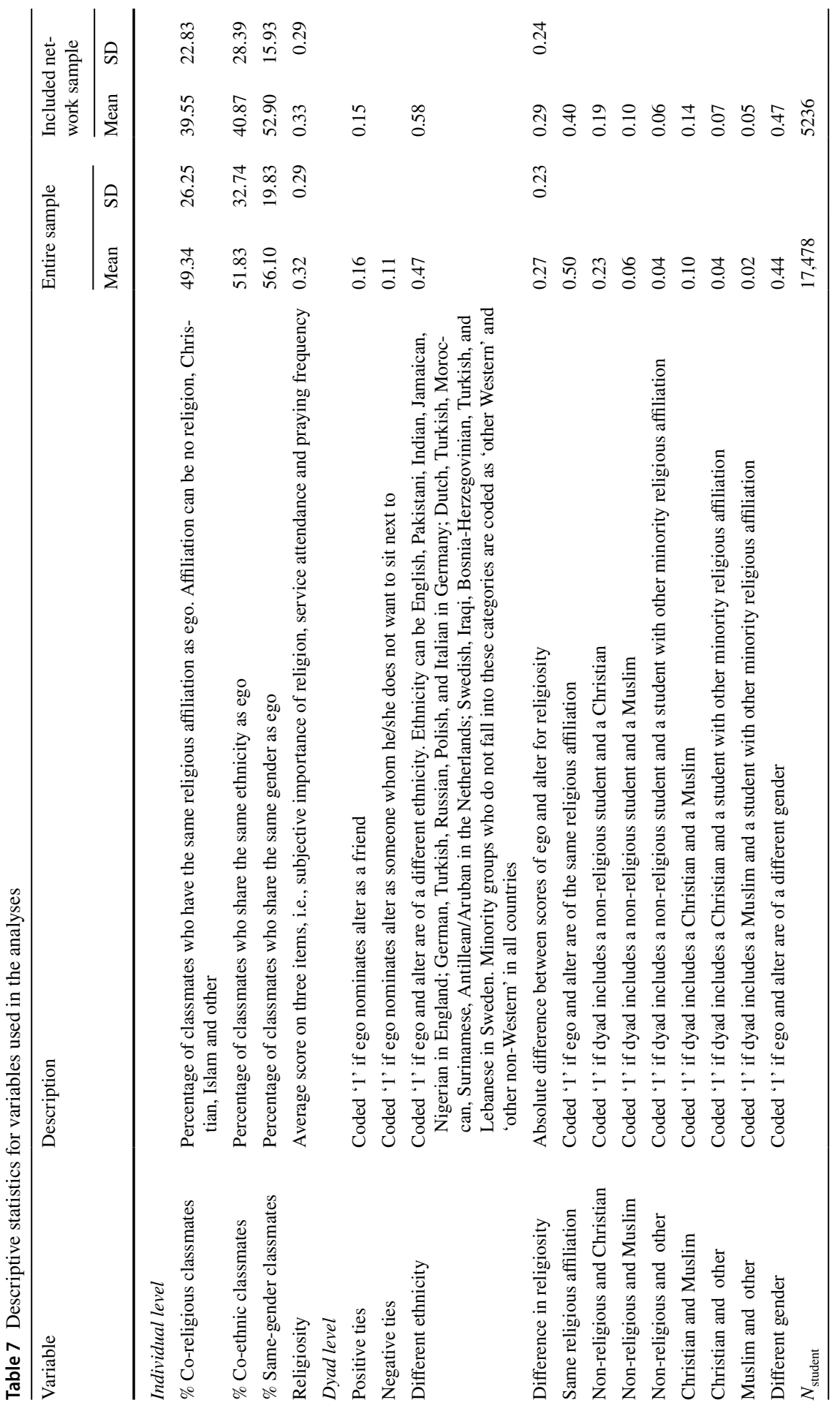




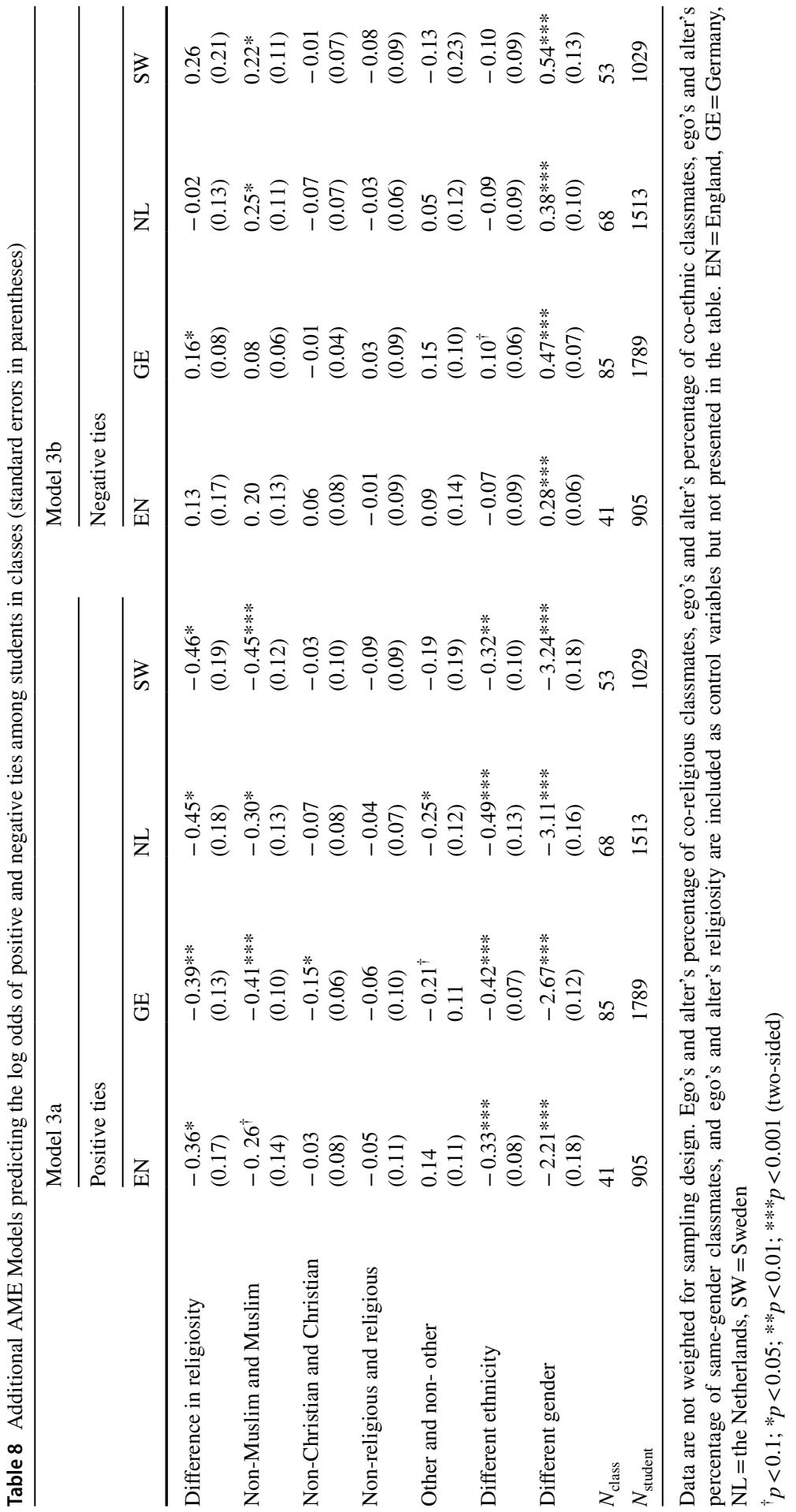




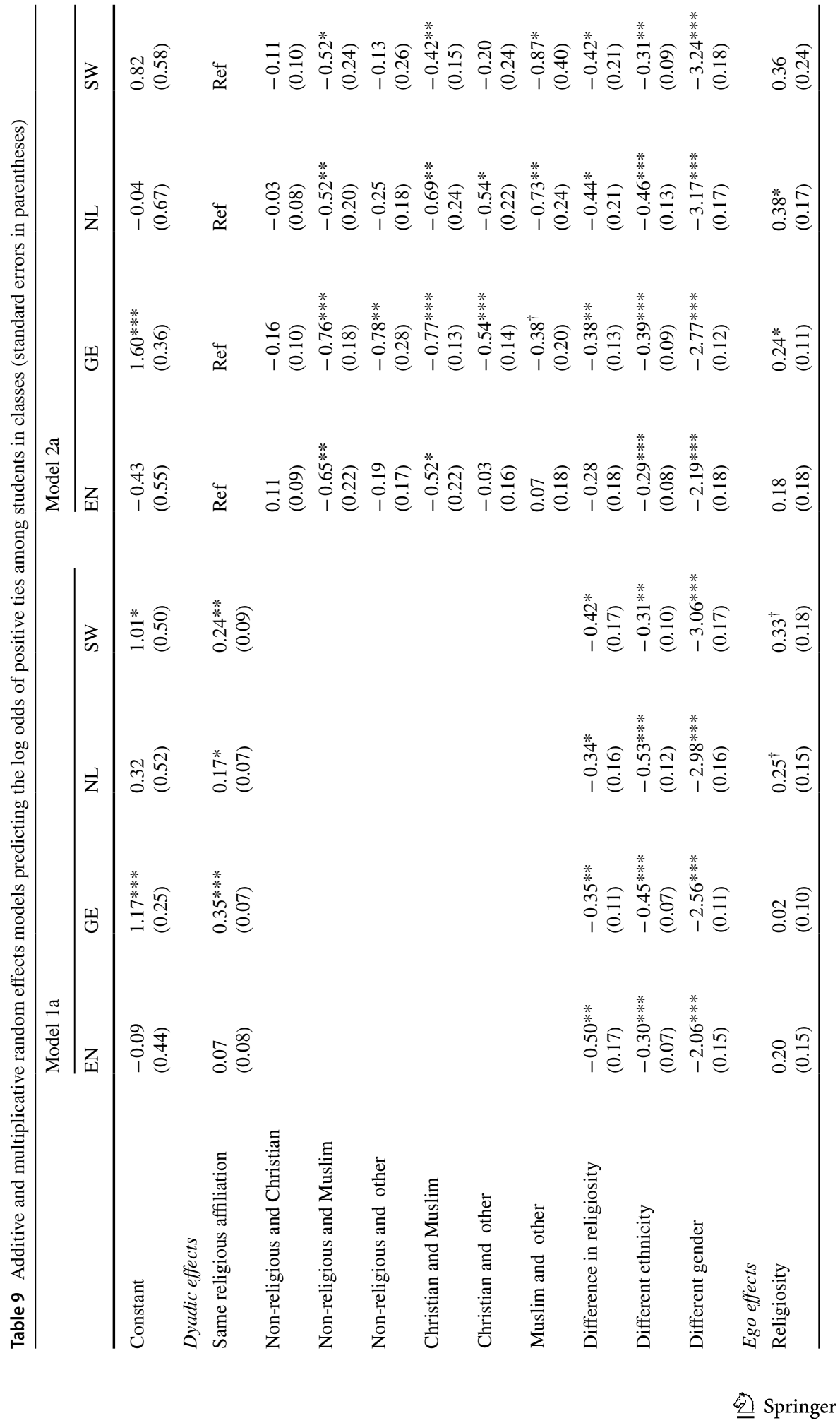




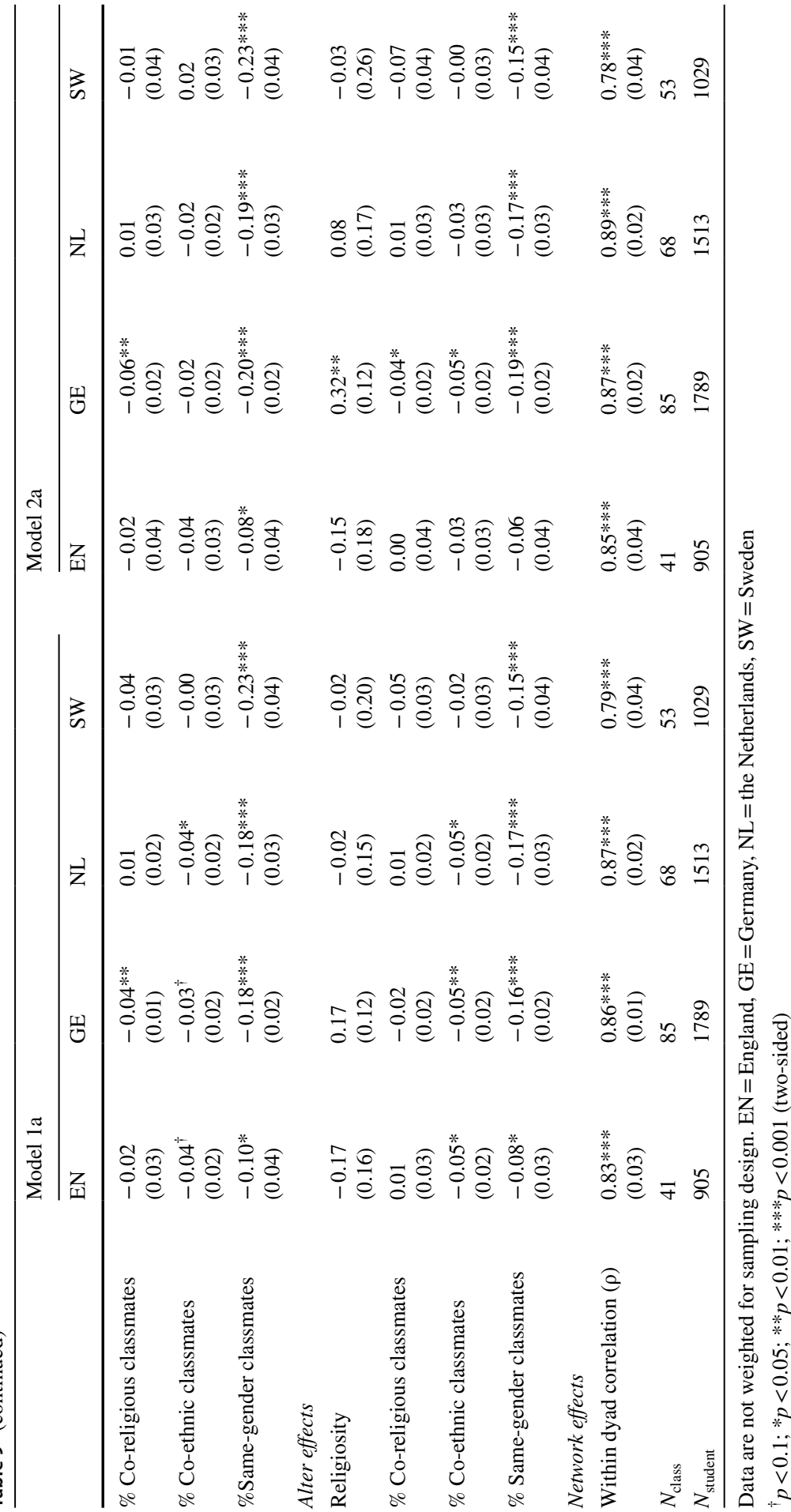




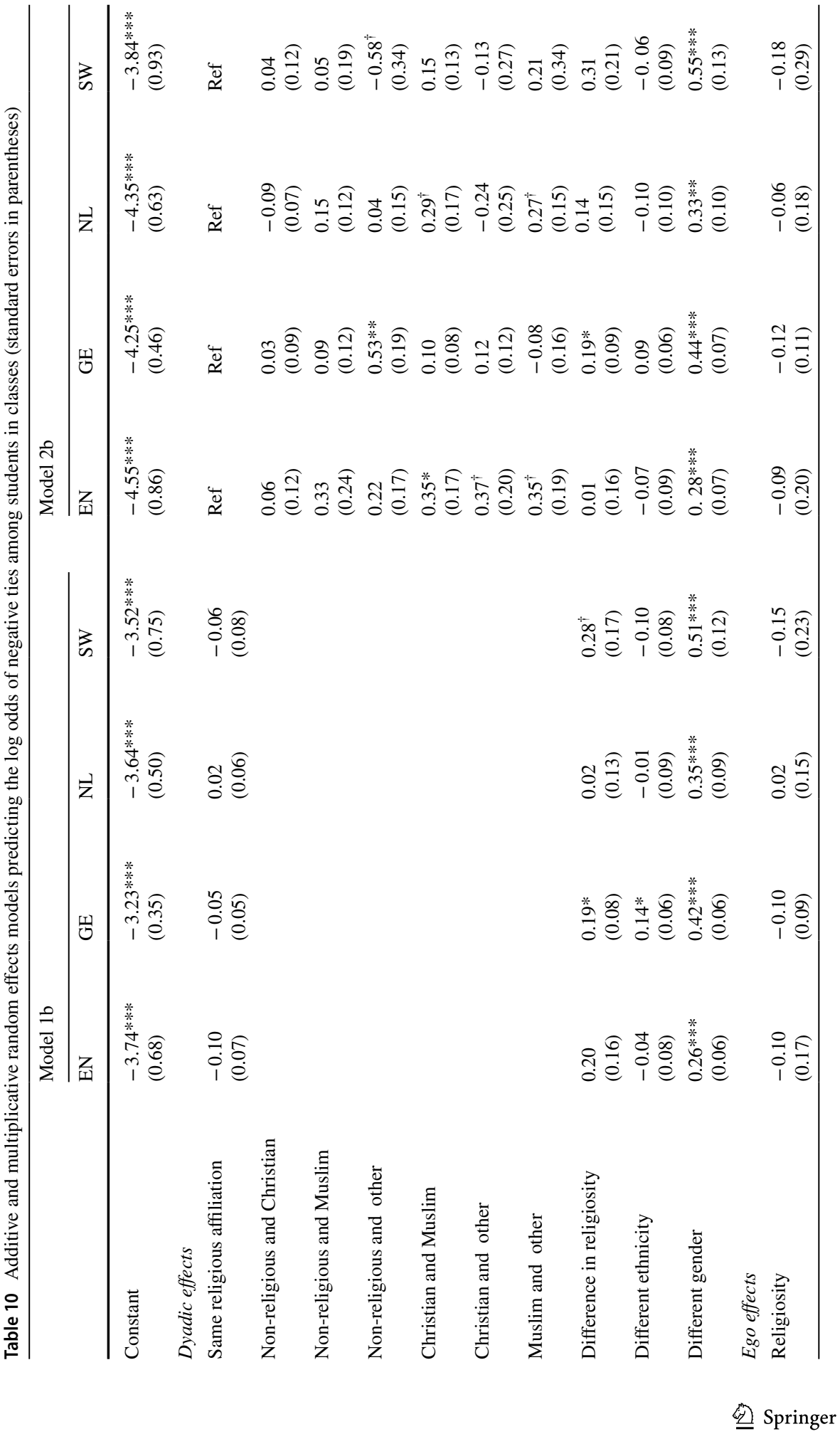




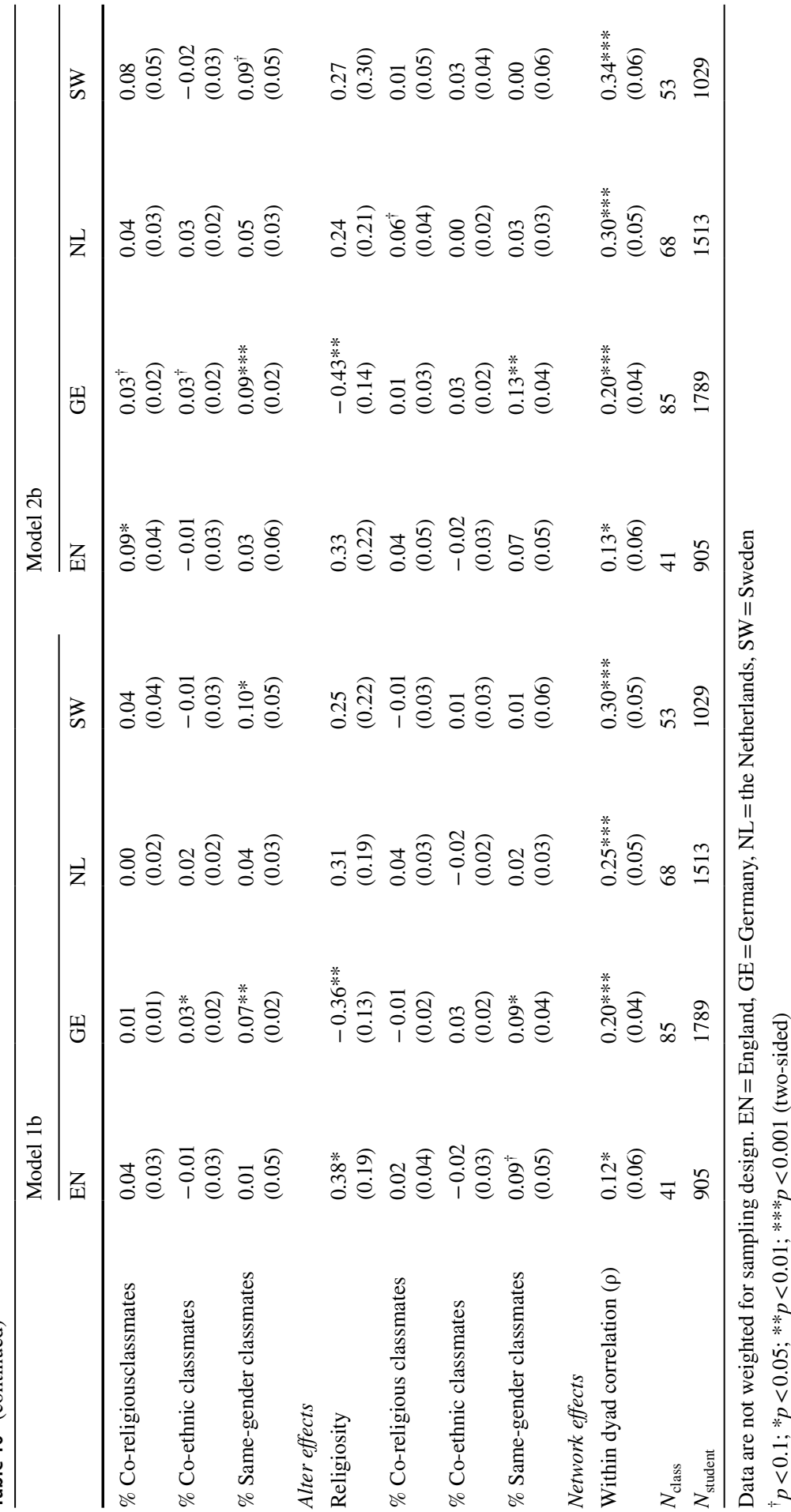




\section{Appendix 2: Robustness Checks}

We performed two types of robustness checks. First, we ran exponential random graph models (ERGMs) in estimating religious homophily in social networks. While additive and multiplicative random effects models allow for the most wellknown third-order dependencies (e.g., transitive triads and stochastic equivalence), ERGMs are especially favored for their ability to provide explicit estimates of a variety of higher-order dependencies (dependence between three or more nodes in the networks) such as higher order stars and two-paths (see Lusher et al. 2013, for an overview of network configurations in ERGMs). However, failure to correctly specify these higher-order dependencies in ERGMs typically results in problems of degeneracy and convergence (Handcock 2003; Wimmer and Lewis 2010). Sparsity in networks also leads to convergence problems and the networks that are suitable for ERG modeling are rather limited in numbers. This is a major shortcoming of ERGMs in relation to our study. Given that we are particularly interested in specific religious boundaries (e.g., do Muslims and Christians befriend each other?), only classes with at least two students from each religious affiliation meet the requirements of ERG modeling. ${ }^{12}$ Moreover, meeting these requirements does not guarantee convergence during ERGM estimation; if there is not at least one tie realized between the students from each religious affiliation, models often do not converge. These convergence problems are exacerbated in negative tie networks due to their sparsity. This implies that we could run the ERGMs on a decent number of classes only for the models testing our hypothesis on general homophily effects and only for friendship networks. Table 11 presents the results of ERGM s. ${ }^{13}$ Differently from AME models, in ERGMs we could include a variable to reflect the marginal returns of additional shared friends (GWESP decay) and get direct coefficient estimates for mutuality, transitivity (by geometrically weighted edgewise shred partner (GWESP)) and for GWESP decay.

The results show that these dependencies substantially contribute to the formation of positive ties among youth. Compared to AME models, the effect sizes of gender and ethnicity homophily are smaller. The effects of same religious affiliation and more particularly of differences in religiosity, on the other hand, are relatively similar between models. Differences between estimates of these two models are not unique to our study and an evaluation of the biases in the estimates between models goes beyond the scope of our study (see Minhas et al. 2016a, b for more empirical comparisons between ERG and AME models). Importantly, the statistical

\footnotetext{
1221 school classes in England and in Germany, 18 classes in the Netherlands and 19 classes in Sweden meet these requirements. If we are only interested in the general homophily effects (e.g., do youth befriend others with the same affiliation?) then the number of classes we can analyze both with ERGs and AME models is higher.

13 Similar to what we did with AME models, we followed a two-step analysis with ERG models; we first ran the ERG models on the same set of classroom friendship networks separately and later combined the results from each network to get a single coefficient estimate and a class dependent deviation. However, in the second stage, due to model degeneracy in total 14 classes are removed from the meta-analysis. Thus, the number of classes shown in Table 11 does not exactly match with that of AME models.
} 
Table 11 ERG models predicting the log odds of positive ties among students in classes (standard errors in parentheses)

\begin{tabular}{|c|c|c|c|c|}
\hline & $\mathrm{EN}$ & GE & NL & SW \\
\hline Edges & $\begin{array}{l}-3.47 * * * \\
(0.12)\end{array}$ & $\begin{array}{l}-3.43^{* * *} \\
(0.06)\end{array}$ & $\begin{array}{l}-3.65^{* * * *} \\
(0.08)\end{array}$ & $\begin{array}{l}-3.76^{* * * *} \\
(0.10)\end{array}$ \\
\hline Mutual & $\begin{array}{l}2.09 * * * \\
(0.15)\end{array}$ & $\begin{array}{l}2.35 * * * \\
(0.07)\end{array}$ & $\begin{array}{l}2.35 * * * \\
(0.10)\end{array}$ & $\begin{array}{l}2.06^{* * * *} \\
(0.11)\end{array}$ \\
\hline Gwesp & $\begin{array}{l}0.67 * * * \\
(0.05)\end{array}$ & $\begin{array}{l}0.68 * * * \\
(0.03)\end{array}$ & $\begin{array}{l}0.81 * * * \\
(0.03)\end{array}$ & $\begin{array}{l}0.73 * * * \\
(0.04)\end{array}$ \\
\hline Gwesp decay & $\begin{array}{l}1.18 * * * \\
(0.14)\end{array}$ & $\begin{array}{l}1.06 * * * \\
(0.08)\end{array}$ & $\begin{array}{l}1.10 * * * \\
(0.09)\end{array}$ & $\begin{array}{l}0.90 * * * \\
(0.11)\end{array}$ \\
\hline Same gender & $\begin{array}{l}0.77 * * * \\
(0.07)\end{array}$ & $\begin{array}{l}0.67 * * * \\
(0.04)\end{array}$ & $\begin{array}{l}0.61 * * * \\
(0.00)\end{array}$ & $\begin{array}{l}0.88 * * * \\
(0.09)\end{array}$ \\
\hline Same ethnicity & $\begin{array}{l}0.17 * * * \\
(0.05)\end{array}$ & $\begin{array}{l}0.19 * * * \\
(0.03)\end{array}$ & $\begin{array}{l}0.10 * * \\
(0.03)\end{array}$ & $\begin{array}{l}0.09 * \\
(0.04)\end{array}$ \\
\hline Difference in religiosity & $\begin{array}{l}-0.33^{* *} \\
(0.10)\end{array}$ & $\begin{array}{l}-0.35^{* * *} \\
(0.06)\end{array}$ & $\begin{array}{l}-0.31 \text { *** } \\
(0.08)\end{array}$ & $\begin{array}{l}-0.31^{* *} \\
(0.10)\end{array}$ \\
\hline Same religious affiliation & $\begin{array}{l}0.06 \\
(0.05)\end{array}$ & $\begin{array}{l}0.14 * * * \\
(0.03)\end{array}$ & $\begin{array}{l}0.12 * * \\
(0.03)\end{array}$ & $\begin{array}{l}0.19 * * * * \\
(0.04)\end{array}$ \\
\hline $\mathrm{N}_{\text {class }}$ & 39 & 82 & 63 & 49 \\
\hline$N_{\text {student }}$ & 851 & 1731 & 1407 & 962 \\
\hline
\end{tabular}

Data are not weighted for sampling design. EN=England, GE=Germany, NL=the Netherlands, $\mathrm{SW}=$ Sweden

${ }^{\dagger} p<0.1 ; * p<0.05 ; * * p<0.01 ; * * * p<0.001$ (two-sided)

significance levels of effects do not deviate much from the AME models (e.g., no significant effects of same affiliation in England), which gives confidence in our interpretation of the existence of boundaries among youth. Overall, we can motivate our choice of the AME over the ERG modeling approach on two grounds. First, we are not interested in the direct effects of structural dependencies on tie formation mechanisms but we only want to account for them in estimating the covariates of our interest. Second and most importantly, ERG models are applicable for testing our hypotheses only with regard to the general homophily mechanisms and only for friendship networks, which defeats the purpose of using an inferential network model for both positive and negative ties in our analyses.

Our second robustness check relates to the second-stage of network analysis. After running AME models for each selected class, we pooled the results across classes by way of univariate random effects meta-analysis, which is a standard approach in network analysis (Lubbers 2003; Riley 2009; Smith et al. 2016). However, this approach assumes that there is zero within-study correlation between the summary estimates and this is unlikely the case in studies where multiple effects are estimated on the same sample (Riley 2009). A multivariate approach to meta-analysis allows taking into account such dependence between multiple estimates from one study (Riley 2009; Jackson et al. 2011). Because parameters estimated in the 
first stage of our analysis are likely to be correlated within classes, we used multivariate random effects models to assess the robustness of our findings. We used the restricted maximum likelihood method to estimate the between-study covariance. However, the multivariate models in which we included the within-study correlation between all parameters did not converge. This was not surprising as the estimating time for an unstructured between-study covariance drastically increases with the number of effects included in the multivariate analysis (White 2011). Because the main focus of the study is on the dyadic homophily measures and the within-study correlation is least likely to be ignorable between ethnic and religious homophily effects, we opted for performing multivariate analyses with only ethnic and religious homophily measures. Results reveal that even though there are minor differences between the estimates from univariate and multivariate meta-analysis models, the results are to a large extent similar across the different models (see Tables 12, 13). More importantly, these minor differences do not affect any of the conclusions we draw regarding the religious boundaries in school classes.

\section{Appendix 3: Model Specification}

A simple version of additive and multiplicative effect models is given by the following specification (Hoff 2015):

$$
\begin{gathered}
y_{i j}=\beta^{T} X_{i j}+a_{i}+b_{j}+\epsilon_{i j}+u_{i}^{T} v_{j} \\
\left\{\left(a_{1}, b_{1}, \ldots,\left(a_{n}, b_{n}\right)\right\}^{\mathrm{idd}} \sim N\left(0, \sum_{a b}\right)\right. \\
\left\{\left(\epsilon_{i j}, \epsilon_{j i}\right): i \neq j\right\}^{\mathrm{idd}} \sim N\left(0, \sum_{\epsilon}\right), \text { where } \\
\sum_{a b}=\left(\begin{array}{cc}
\sigma_{a}^{2} & \sigma_{a b} \\
\sigma_{a b} & \sigma_{b}^{2}
\end{array}\right) \quad \sum_{\epsilon}=\sigma_{\epsilon}^{2}\left(\begin{array}{ll}
1 & \rho \\
\rho & 1
\end{array}\right)
\end{gathered}
$$

$\beta^{T} X_{i, j}$ accommodates the inclusion of dyadic, ego, and alter covariates. Whereas $a_{i}+b_{j}+\epsilon_{i j}$ refers to the additive random effects accounting for first and second order dependencies, $u_{i}^{T} v_{j}$ represents the multiplicative effects that capture the higher-order dependencies within the AME framework. In particular, ego/sender effects $\left(a_{i}\right)$ and alter/receiver effects $\left(b_{i}\right)$ describe the variability in how active the actors are in sending and receiving ties. These heterogeneities are summarized by $\sigma_{a}^{2}$ and $\sigma_{b}^{2}$, and $\sigma_{a b}$ expresses the linear relationship between the ego and alter effects. $\sigma_{\epsilon}^{2}$ captures the additional variability across dyads, $\rho$ is the within dyad correlation (reciprocity), and $u_{i}$ and $v_{j}$ are vectors of latent factors for both the ego and alter. 


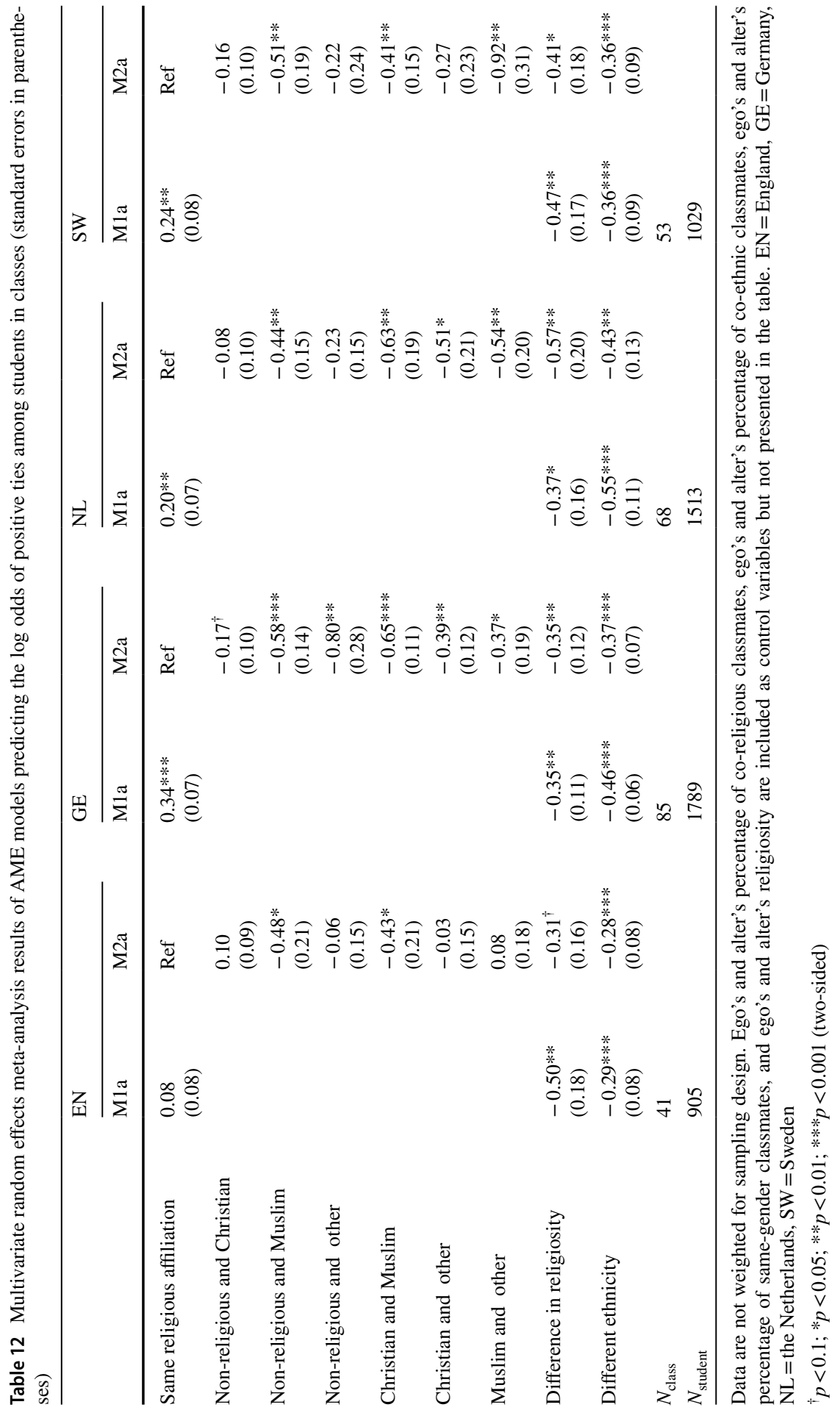


Table 13 Multivariate random effects meta-analysis results of AME models predicting the log odds of negative ties among students in classes (standard errors in parentheses)

\begin{tabular}{|c|c|c|c|c|c|c|c|c|}
\hline & \multicolumn{2}{|l|}{ EN } & \multicolumn{2}{|l|}{ GE } & \multicolumn{2}{|l|}{ NL } & \multicolumn{2}{|l|}{ SW } \\
\hline & M1b & M2b & M1b & $\mathrm{M} 2 \mathrm{~b}$ & M1b & $\mathrm{M} 2 \mathrm{~b}$ & M1b & $\mathrm{M} 2 \mathrm{~b}$ \\
\hline Same religious affiliation & $\begin{array}{l}-0.08 \\
(0.07)\end{array}$ & Ref & $\begin{array}{l}-0.08^{\dagger} \\
(0.05)\end{array}$ & Ref & $\begin{array}{l}0.01 \\
(0.06)\end{array}$ & Ref & $\begin{array}{l}-0.05 \\
(0.07)\end{array}$ & Ref \\
\hline Non-religious and Christian & & $\begin{array}{l}0.06 \\
(0.10)\end{array}$ & & $\begin{array}{l}-0.00 \\
(0.08)\end{array}$ & & $\begin{array}{l}-0.11 \\
(0.07)\end{array}$ & & $\begin{array}{l}0.02 \\
(0.10)\end{array}$ \\
\hline Non-religious and Muslim & & $\begin{array}{l}0.22 \\
(0.20)\end{array}$ & & $\begin{array}{l}0.14 \\
(0.12)\end{array}$ & & $\begin{array}{l}0.08 \\
(0.11)\end{array}$ & & $\begin{array}{l}0.06 \\
(0.16)\end{array}$ \\
\hline Non-religious and other & & $\begin{array}{l}0.03 \\
(0.17)\end{array}$ & & $\begin{array}{l}0.49 * * \\
(0.16)\end{array}$ & & $\begin{array}{l}-0.06 \\
(0.13)\end{array}$ & & $\begin{array}{l}-0.47 \\
(0.31)\end{array}$ \\
\hline Christian and Muslim & & $\begin{array}{l}0.20 \\
(0.15)\end{array}$ & & $\begin{array}{l}0.11 \\
(0.07)\end{array}$ & & $\begin{array}{l}0.14 \\
(0.14)\end{array}$ & & $\begin{array}{l}0.12 \\
(0.11)\end{array}$ \\
\hline Christian and other & & $\begin{array}{l}0.14 \\
(0.16)\end{array}$ & & $\begin{array}{l}0.19^{\dagger} \\
(0.11)\end{array}$ & & $\begin{array}{l}-0.34 \\
(0.21)\end{array}$ & & $\begin{array}{l}-0.19 \\
(0.28)\end{array}$ \\
\hline Muslim and other & & $\begin{array}{l}0.18 \\
(0.20)\end{array}$ & & $\begin{array}{l}0.01 \\
(0.16)\end{array}$ & & $\begin{array}{l}0.20 \\
(0.16)\end{array}$ & & $\begin{array}{l}0.38 \\
(0.29)\end{array}$ \\
\hline Difference in religiosity & $\begin{array}{l}0.23 \\
(0.16)\end{array}$ & $\begin{array}{l}0.18 \\
(0.16)\end{array}$ & $\begin{array}{l}0.21 * \\
(0.08)\end{array}$ & $\begin{array}{l}0.22 * \\
(0.09)\end{array}$ & $\begin{array}{l}0.13 \\
(0.13)\end{array}$ & $\begin{array}{l}0.21 \\
(0.14)\end{array}$ & $\begin{array}{l}0.26 \\
(0.16)\end{array}$ & $\begin{array}{l}0.26 \\
(0.19)\end{array}$ \\
\hline Different ethnicity & $\begin{array}{l}-0.03 \\
(0.08)\end{array}$ & $\begin{array}{l}-0.06 \\
(0.09)\end{array}$ & $\begin{array}{l}0.13^{*} \\
(0.06)\end{array}$ & $\begin{array}{l}0.12^{\dagger} \\
(0.06)\end{array}$ & $\begin{array}{l}0.03 \\
(0.09)\end{array}$ & $\begin{array}{l}-0.03 \\
(0.10)\end{array}$ & $\begin{array}{c}-0.10 \\
(0.08)\end{array}$ & $\begin{array}{l}-0.08 \\
(0.09)\end{array}$ \\
\hline$N_{\text {class }}$ & 41 & & 85 & & 68 & & 53 & \\
\hline$N_{\text {student }}$ & 905 & & 1789 & & 1513 & & 1029 & \\
\hline
\end{tabular}

Data are not weighted for sampling design. Ego's and alter's percentage of co-religious classmates, ego's and alter's percentage of co-ethnic classmates, ego's and alter's percentage of same-gender classmates, and ego's and alter's religiosity are included as control variables but not presented in the table. $\mathrm{EN}=$ England, $\mathrm{GE}=$ Germany, $\mathrm{NL}=$ the Netherlands, $\mathrm{SW}=$ Sweden

${ }^{\dagger} p<0.1 ; * p<0.05$; ** $p<0.01$; *** $p<0.001$ (two-sided)

Acknowledgements The data used in this study may be obtained for purposes of replication and are available from GESIS Data Archive for the Social Sciences in Cologne, Germany. This research benefited from the support of the NORFACE research program on Migration in Europe - Social, Economic, Cultural and Policy Dynamics and from the support of the Dutch Scientific Organization (NWO); [Grant Number: RLG-12-25].

Open Access This article is licensed under a Creative Commons Attribution 4.0 International License, which permits use, sharing, adaptation, distribution and reproduction in any medium or format, as long as you give appropriate credit to the original author(s) and the source, provide a link to the Creative Commons licence, and indicate if changes were made. The images or other third party material in this article are included in the article's Creative Commons licence, unless indicated otherwise in a credit line to the material. If material is not included in the article's Creative Commons licence and your intended use is not permitted by statutory regulation or exceeds the permitted use, you will need to obtain permission directly from the copyright holder. To view a copy of this licence, visit http://creativecommons.org/licen ses/by/4.0/. 


\section{References}

Adida, Claire L., David D. Laitin, and Marie-Anne. Valfort. 2016. Why Muslim Integration Fails in Christian-Heritage Societies. Cambridge: Harvard University Press.

Baerveldt, Chris, Bonne Zijlstra, Muriel de Wolf, Ronan Van Rossem, and Marijtje A. J. Van Duijn. 2007. Ethnic Boundaries in High School Students' Networks in Flanders and the Netherlands. International Sociology 22 (6): 701-720. https://doi.org/10.1177/0268580907082248.

Bartkoski, Timothy, Ellen Lynch, Chelsea Witt, and Cort Rudolph. 2018. A Meta-Analysis of Hiring Discrimination Against Muslims and Arabs. Personnel Assessment and Decisions 4 (2): 1-16.

Blau, Peter Michael. 1977. Inequality and heterogeneity: A primitive theory of social structure. Vol. 7. New York: Free Press.

Blau, Peter M., Terry C. Blum, and Joseph E. Schwartz. 1982. Heterogeneity and Intermarriage. American Sociological Review 47 (1): 45. https://doi.org/10.2307/2095041.

Blommaert, Lieselotte, Marcel Coenders, and Frank van Tubergen. 2014. Discrimination of ArabicNamed Applicants in the Netherlands: An Internet-Based Field Experiment Examining Different Phases in Online Recruitment Procedures. Social Forces 92 (3): 957-982. https://doi.org/10.1093/ sf/sot124.

Boda, Zsófia., and Bálint. Néray. 2015. Inter-ethnic friendship and negative ties in secondary school. Social Networks 43: 57-72.

Burkimsher, Marion. 2014. Is religious attendance bottoming out? An examination of current trends across Europe. Journal for the Scientific Study of Religion 53(2): 432-445.

Byrne, Donn. 1961. Interpersonal Attraction and Attitude Similarity. Journal of Abnormal and Social Psychology 62 (3): 713-715. https://doi.org/10.1037/h0044721.

Carol, Sarah, Marc Helbling, and Ines Michalowski. 2015. A Struggle Over Religious Rights? How Muslim Immigrants and Christian Natives View the Accommodation of Religion in Six European Countries. Social Forces 94 (2): 647-671.

CILS4EU. 2016a. Children of Immigrants Longitudinal Survey in Four European Countries. Technical Report. Wave 1-2012/2013, v3.1.0. Mannheim: Mannheim University.

CILS4EU. 2016b. Children of Immigrants Longitudinal Survey in Four European Countries. Technical Report. Wave 3-2012/2013, v3.1.0. Mannheim: Mannheim University.

De Haas, Hein, Mark J. Miller, and Stephen Castles. 2019. The Age of Migration: International Population Movements in the Modern World. Red Globe Press.

De Hoon, Sean, and Frank van Tubergen. 2014. The Religiosity of Children of Immigrants and Natives in England, Germany, and the Netherlands: The Role of Parents and Peers in Class. European Sociological Review 30 (2): 194-206.

Dijkstra, Jan Kornelis, Siegwart Lindenberg, and René Veenstra. 2007. Same-Gender and Cross-Gender Peer Acceptance and Peer Rejection and Their Relation to Bullying and Helping Among Preadolescents: Comparing Predictions from Gender-Homophily and Goal-Framing Approaches. Developmental Psychology 43 (6): 1377.

Di Stasio, Valentina, Bram Lancee, Susanne Veit, and Ruta Yemane. 2019. Muslim by Default or Religious Discrimination? Results from a Cross-National Field Experiment on Hiring Discrimination. Journal of Ethnic and Migration Studies 47: 1305-1326.

Doebler, Stefanie. 2014. Relationships Between Religion and Intolerance Towards Muslims and Immigrants in Europe: A Multilevel Analysis. Review of Religious Research 56 (1): 61-86.

Dorff, Cassy, and Michael D. Ward. 2013. Networks, Dyads, and the Social Relations Model. Political Science Research and Methods 1 (2): 159-178.

Drouhot, Lucas G., and Victor Nee. 2019. Assimilation and the Second Generation in Europe and America: Blending and Segregating Social Dynamics Between Immigrants and Natives. Annual Review of Sociology 45: 177-199.

Durkheim, Emile. 2008[1912]. The Elementary Forms of the Religious Life. Translated by J.Swan. Courier Corporation.

European Social Survey. 2014. Data file edition 2.2. NSD - Norwegian Centre for Research Data, Norway - Data Archive and distributor of ESS data for ESS ERIC. https://doi.org/10.21338/ NSD-ESS7-2014.

Eurostat. 2011. Migrants in Europe. A Statistical Portrait of First and Second Generation. Luxembourg: European Union. 
Foner, N. 2015. Is Islam in Western Europe Like Race in the United States? Sociological Forum 30: $885-899$.

Foner, Nancy, and Richard Alba. 2008. Immigrant Religion in the U.S. and Western Europe: Bridge or Barrier to Inclusion? International Migration Review 42 (2): 360-392.

Fosdick, Bailey K., and Peter D. Hoff. 2015. Testing and Modeling Dependencies Between a Network and Nodal Attributes. Journal of the American Statistical Association 110 (511): 1047-1056.

Handcock, Mark S. 2003. Statistical Models for Social Networks: Degeneracy and Inference. In Dynamic Social Network Modeling and Analysis, ed. Ronald Breiger, R. Kathleen Carley, and Philippa Pattison, 229-240. Washington DC: National Academies Press.

Hoff, Peter D. 2015. Dyadic Data Analysis with Amen. arXiv preprint arXiv:1506.08237.

Jacob, Konstanze, and Frank Kalter. 2013. Intergenerational Change in Religious Salience Among Immigrant Families in Four European Countries. International Migration 51 (3): 38-56.

Jackson, Lynne M., and Bruce Hunsberger. 1999. An Intergroup Perspective on Religion and Prejudice. Journal for the Scientific Study of Religion 38 (4): 509-523.

Jackson, Dan, Richard Riley, and Ian R. White. 2011. Multivariate Meta-Analysis: Potential and Promise. Statistics in Medicine 30 (20): 2481-2498. https://doi.org/10.1002/sim.4172.

Johnson, Megan K., Wade C. Rowatt, and Jordan P. LaBouff. 2012. Religiosity and Prejudice Revisited: In-Group Favoritism, Out-Group Derogation, or Both? Psychology of Religion and Spirituality 4 (2): 154.

Kalmijn, Matthijs. 1998. Intermarriage and Homogamy: Causes, Patterns, Trends. Annual Review of Sociology 24 (24): 395-421. https://doi.org/10.1146/annurev.soc.24.1.395.

Kalter, Frank, Anthony F. Heath, Miles Hewstone, Jan O. Jonsson, Matthijs Kalmijn, Irene Kogan, and Frank van Tubergen. 2016. Children of Immigrants Longitudinal Survey in Four European Countries (CILS4EU)_Full Version. Data file for on-site use. GESIS Data Archive, Cologne, ZA5353 Data file Version 1.2.0. https://doi.org/10.4232/cils4eu.5353.1.2.0.

Kandel, Denise B. 1978. Homophily, Selection, and Socialization in Adolescent Friendships. American Journal of Sociology 84 (2): 427-436.

Kruse, Hanno, Sanne Smith, Frank van Tubergen, and Ineke Maas. 2016. From neighbors to school friends? How adolescents' place of residence relates to same-ethnic school friendships. Social Networks 44: 130-142.

Lamont, Michèle, and Virág Molnár. 2002. The Study of Boundaries in the Social Sciences. Annual Review of Sociology 28 (1): 167-195.

Leszczensky, Lars, and Sebastian Pink. 2017. Intra- and Inter-group Friendship Choices of Christian, Muslim, and Non-religious Youth in Germany. European Sociological Review 33 (1): 72-83. https://doi.org/10.1093/esr/jcw049.

Lubbers, Miranda J. 2003. Group Composition and Network Structure in School Classes: A Multilevel Application of the p* Model. Social Networks 25 (4): 309-332. https://doi.org/10.1016/S03788733(03)00013-3.

Lucassen, Leo, and Charlotte Laarman. 2009. Immigration, Intermarriage and the Changing Face of Europe in the Post War Period. History of the Family 14: 52-68. https://doi.org/10.1016/j.hisfam. 2008.12.001.

Lusher, Dean, Johan Koskinen, and Garry Robins, eds. 2013. Exponential Random Graph Models for Social Networks: Theory, Methods, and Applications. Cambridge: Cambridge University Press.

Mayer, Adalbert, and Steven L. Puller. 2008. The Old Boy (and Girl) Network: Social Network Formation on University Campuses. Journal of Public Economics 92 (1-2): 329-347. https://doi.org/10. 1016/j.jpubeco.2007.09.001.

McPherson, Miller, Lynn Smith-Lovin, and James M. Cook. 2001. Birds of a Feather: Homophily in Social Networks. Annual Review of Sociology 27 (1): 415-444. https://doi.org/10.1146/annurev.soc. 27.1.415.

Minhas, Shahryar, Peter D. Hoff, and Michael D. Ward. 2016a. Inferential Approaches for Network Analyses: Amen for Latent Factor Models. arXiv preprint arXiv:1611.00460.

Minhas, Shahryar, Peter D. Hoff, and Michael D. Ward. 2016b. A New Approach to Analyzing Coevolving Longitudinal Networks in International Relations. Journal of Peace Research 53 (3): 491-505.

Moody, James. 2001. Race, School Integration and Frienship Segregation in America. American Journal of Sociology 107 (3): 679-716. 
Mummendey, Amélle., and Hans-Joachim. Schreiber. 1983. Better or Just Different? Positive Social Identity by Discrimination against, or by Differentiation from Outgroups. European Journal of Social Psychology 13 (4): 389-397.

Munniksma, Anke, Peer Scheepers, Tobias H. Stark, and Jochem Tolsma. 2017. The impact of adolescents' classroom and neighborhood ethnic diversity on same-and cross-ethnic friendships within classrooms. Journal of Research on Adolescence 27(1): 20-33.

Norris, Pippa, and Ronald Inglehart. 2011. Sacred and Secular: Religion and Politics Worldwide. Cambridge: Cambridge University Press.

Poulin, François, and Sara Pedersen. 2007. Developmental Changes in Gender Composition of Friendship Networks in Adolescent Girls and Boys. Developmental Psychology 43 (6): 1484.

Riley, Richard D. 2009. Multivariate Meta-Analysis: The Effect of Ignoring Within-Study Correlation. Journal of the Royal Statistical Society: Series A (statistics in Society) 172 (4): 789-811.

Simonsen, Kristina B., and Bart Bonikowski. 2020. Is Civic Nationalism Necessarily Inclusive? Conceptions of Nationhood and Anti-Muslim Attitudes in Europe. European Journal of Political Research 59 (1): 114-136.

Smith, Sanne, Ineke Maas, and Frank van Tubergen. 2014. Ethnic Ingroup Friendships in Schools: Testing the By-Product Hypothesis in England, Germany, the Netherlands and Sweden. Social Networks 39 (1): 33-45. https://doi.org/10.1016/j.socnet.2014.04.003.

Smith, Sanne, Daniel A. McFarland, Ineke Maas, and Frank van Tubergen. 2016. Ethnic Composition and Friendship Segregation: Differential Effects for Adolescent Natives and Immigrants. American Journal of Sociology 121 (4): 1223-1272.

Snijders, Tom AB., and Chris Baerveldt. 2003. A Multilevel Network Study of the Effects of Delinquent Behavior on Friendship Evolution. Journal of Mathematical Sociology 27 (2-3): 123-151.

Strabac, Zan, and Ola Listhaug. 2008. Anti-Muslim Prejudice in Europe: A Multilevel Analysis of Survey Data from 30 Countries. Social Science Research 37 (1): 268-286.

Tolsma, Jochem, Ioana van Deurzen, Tobias H. Stark, and René Veenstra. 2013. Who is Bullying Whom in Ethnically Diverse Primary Schools? Exploring Links between Bullying, Ethnicity, and Ethnic diversity in Dutch Primary Schools. Social Networks 35 (1): 51-61. https://doi.org/10.1016/j.socnet. 2012.12.002.

Trittler, Sabine. 2019. Consequences of Religious and Secular Boundaries Among the Majority Population for Perceived Discrimination Among Muslim Minorities in Western Europe. Journal of Ethnic and Migration Studies 45 (7): 1127-1147.

Van Tubergen, Frank, and Jorunn I. Sindradottir. 2011. The religiosity of immigrants in Europe: A crossnational study. Journal for the scientific study of religion 50(2): 272-288.

Voas, David, and Fenella Fleischmann. 2012. Islam Moves West: Religious Change in the First and Second Generations. Annual Review of Sociology 38 (1): 525-545.

Veroniki, AretiAngeliki, Dan Jackson, Wolfgang Viechtbauer, Ralf Bender, Jack Bowden, Guido Knapp, Oliver Kuss, Julian PT. Higgins, Dean Langani, and Georgia Salantij. 2015. Methods to Estimate the Between-Study Variance and Its Uncertainty in Meta-Analysis. Research Synthesis Methods 7 (1): 55-79. https://doi.org/10.1002/jrsm.1164.

White, Ian R. 2011. Multivariate Random-Effects Meta-Regression: Updates to Mvmeta. Stata Journal 11 (2): 255.

Windzio, Michael, and Matthias Wingens. 2014. Religion, Friendship Networks and Home Visits of Immigrant and Native Children. Acta Sociologica 57 (1): 59-75. https://doi.org/10.1177/00016 99313481226.

Wimmer, Andreas. 2008. The Making and Unmaking of Ethnic Boundaries: A Multilevel Process Theory. American Journal of Sociology 113 (4): 970-1022.

Wimmer, Andreas, and Kevin Lewis. 2010. Beyond and Below Racial Homophily: ERG Models of a Friendship Network Documented on Facebook. American Journal of Sociology 116 (2): 583-642. https://doi.org/10.1086/653658.

Wittek, Mark, Clemens Kroneberg, and Kathrin Lämmermann. 2019. Who is Fighting with Whom? How Ethnic Origin Shapes Friendship, Dislike, and Physical Violence Relations in German Secondary Schools. Social Networks 60: 34-47.

Zeng, Zhen, and Yu. Xie. 2008. A Preference-Opportunity-Choice Framework with Applications to Intergroup Friendship. American Journal of Sociology 114 (3): 615-648. https://doi.org/10.1086/ 592863. 
Zolberg, Aristide R., and Long Litt Woon. 1999. Why Islam Is like Spanish: Cultural Incorporation in Europe and the United States. Politics \& Society 27 (1): 5-38.

Publisher's Note Springer Nature remains neutral with regard to jurisdictional claims in published maps and institutional affiliations.

\section{Authors and Affiliations}

\section{Müge Simsek $^{1}\left[\right.$ [ Frank van Tubergen ${ }^{2} \cdot$ Fenella Fleischmann ${ }^{3}$}

$\triangle$ Müge Simsek

m.simsek@uu.nl

1 Utrecht University, Utrecht, The Netherlands

2 Netherlands Interdisciplinary Demographic Institute (NIDI), KNAW, University of Groningen, The Hague, Groningen, Netherlands

3 European Research Centre on Migration and Ethnic Relations, Utrecht University, Utrecht, The Netherlands 